\title{
1. Evidences of horizontal urban heat advection in London using 6 years of data from a citizen weather station network
}

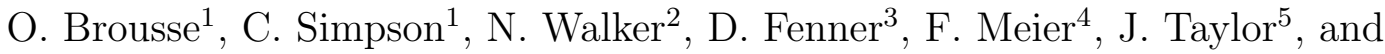 \\ C. Heaviside ${ }^{1}$
}

${ }^{1}$ UCL Institute for Environmental Design and Engineering, The Bartlett Faculty of Environment, University College London, London, United-Kingdom

${ }^{2}$ Bioengineering Sciences Research Group, Department of Mechanical Engineering, School of Engineering, Faculty of Engineering and Physical Sciences, University of Southampton, United Kingdom

${ }^{3}$ Chair of Environmental Meteorology, Institute of Earth and Environmental Sciences, Faculty of Environment and Natural Resources, University of Freiburg, Germany

${ }^{4}$ Chair of Climatology, Institute of Ecology, Technische Universität Berlin, Germany ${ }^{5}$ Department of Civil Engineering, Tampere University, Tampere, Finland

December 2021

\section{Corresponding author: Dr. Oscar Brousse, o.brousse@ucl.ac.uk}

This document is a preprint of the manuscript submitted on the $2^{\text {nd }}$ of December 2021 to Environmental Research Letters (ERL). This paper has not followed any peer-review at this stage and is submitted to EarthArXiv in its submitted form to ERL. For additional information, please contact Dr. Oscar Brousse at o.brousse@ucl.ac.uk.

\begin{abstract}
Recent advances in citizen weather station (CWS) networks, with data accessible via crowdsourcing, provide relevant climatic information to urban scientists and decision makers. In particular, CWS can provide long-term measurements of urban heat and valuable information on spatio-temporal heterogeneity related to horizontal heat advection. In this study, we make the first compilation of a quasi-climatologic dataset covering 6 years (2015-2020) of hourly near-surface air temperature measurements obtained via 1560 suitable CWS in a domain covering south-east England and Greater London. We investigated the spatio- temporal distribution of urban heat and the influences of local environments on climate, captured by CWS through the scope of Local Climate Zones (LCZ) - a land-use land-cover classification specifically designed for urban climate studies. We further calculate, for the first time, the amount of advected heat captured by CWS located in Greater London and the wider south east England region. We find that London is on average warmer by $\sim 1.0{ }^{\circ} \mathrm{C}$ to $\sim 2.0{ }^{\circ} \mathrm{C}$ than the rest of south-east England. Characteristics of the southern coastal climate are also captured in the analysis. We find that on average, urban heat advection (UHA) contributes to $0.22{ }^{\circ} \mathrm{C}$ of the total urban heat in Greater London. Certain areas, mostly in the centre of London are deprived of urban heat through advection since heat is transferred more to downwind suburban areas. UHA can positively contribute to urban heat by up to $\sim 2.0^{\circ} \mathrm{C}$ on average and negatively by down to $\sim-1.0{ }^{\circ} \mathrm{C}$. Our results also show an important degree of inter- and intra-LCZ variability in UHA, calling for more research in the future. Nevertheless, we already find that UHA can impact green areas and reduce their cooling benefit. Such outcomes show the added value of CWS for future urban design.
\end{abstract}




\section{Introduction}

Recent studies have highlighted growing interest and opportunities for urban climate studies using crowd-sourced urban meteorological data (Steeneveld et al., 2011; Wolters and Brandsma, 2012; Muller et al., 2015; de Vos et al., 2020). Among a variety of crowd-sourcing devices, citizen weather stations (CWS) - also sometimes referred to as personal weather stations - have been gaining popularity. Since their evaluation against official automatic weather stations measurements (Bell et al., 2015), CWS were sought to help measuring urban temperatures in large cities Meier et al. (2017); Chapman et al. (2017). In fact, CWS increases the potential for improved geographical coverage of observations in cities, rather than only relying on established official meteorological stations, which are often lacking in numbers within cities and therefore in representation of urban climate features (Oke et al., 2004; Grimmond, 2006; Muller et al., 2013). Although CWS are subject to greater uncertainties, quality-checking procedures for air-temperature data exist either based on CWS biases against official automatic weather stations located at a certain distance (Meier et al., 2017; Hammerberg et al., 2018) or on statistics among CWS alone (Napoly et al., 2018; Fenner et al., 2021).

The potential applications of CWS are wide and continue to expand. For example, recent studies have used CWS to improve our understanding of the impact of land-use and land-cover on urban temperatures through the perspective of Local Climate Zones (LCZ; a land-use and land-cover classification specifically developed for urban climate studies (Stewart and Oke, 2012); Fenner et al. (2017); Benjamin et al. (2021); Potgieter et al. (2021); Varentsov et al. (2021)). Others have used CWS to validate urban climate simulations (Hammerberg et al., 2018), drive indoor-temperatures in urban climate simulations Jin et al. (2021), and have used them to model air temperatures in European cities using machine learning (Venter et al., 2020; Vulova et al., 2020; Venter et al., 2021; Zumwald et al., 2021). Research using CWS has not been limited to urban temperature; some have used them to monitor (urban) precipitation (de Vos et al., 2019, 2020) or wind speed (Droste et al., 2020) - allowing for the development of an innovative quality-check for crowd-sourced wind data (Chen et al., 2021).

Nowadays, most research at the time of writing has focused on short time periods that do not extend beyond a year and usually focus on summer periods only. This means that multiple years climatology have not yet been performed. Nonetheless, Meier et al. (2017); Fenner et al. (2017) both studied the whole year climatology in the city of Berlin using CWS and characterized some intra-urban variability of urban temperatures among different LCZ. Additionally, Fenner, Daniel and Holtmann, Achim and Meier, Fred and Langer, Ines and Scherer, Dieter (2019) used CWS to study the variability of urban heat island intensities during heatwave events in the extended summer season (May to September) of 2015 to 2018. They did not, however, look at the winter. Apart from Venter et al. (2021), who studied urban heat islands among multiple European cities for one summer month in 2019, large-scale analyses (e.g., regional, national or continental) have also not been extensively performed. As such, most of the studies focus on single cities only. Lastly, while some studies have already investigated the weather-dependent variability of the urban heat islands using CWS (e.g., Chapman et al. (2017)), none have yet studied how certain prevailing winds may cause horizontal urban heat advection (UHA) and the sensitivity of CWS to this advected heat.

In fact, previous studies show that UHA impacts the spatial distribution of urban heat (Heaviside et al., 2015; Bassett et al., 2016). UHA can be considered as the heat resulting from the windborne transport of energy among the urban environment (Oke et al., 2017). It is often neglected because modelling and observational studies of urban heat tend to assume that horizontal diffusion is similar across the urban landscape and that major heat production comes from differences in surface energy balance related to land-use land-cover. Nevertheless, a modelling study of the August 2003 heatwave in the city of Birmingham, England, Heaviside et al. (2015) showed that UHA can reach up to $2.5{ }^{\circ} \mathrm{C}$, particularly under north-westerly and south-easterly wind conditions. Using a dense network of professional weather stations in the same city, Bassett et al. (2016) showed a mean UHA over a 20-months period (January 2013 to September 2014) of $1.2{ }^{\circ} \mathrm{C}$, and argued that it could be higher under certain specific conditions as shown in Heaviside et al. (2015). This demonstrates that UHA can have a significant impact on urban temperatures, and needs to be properly understood to develop future urban heat 


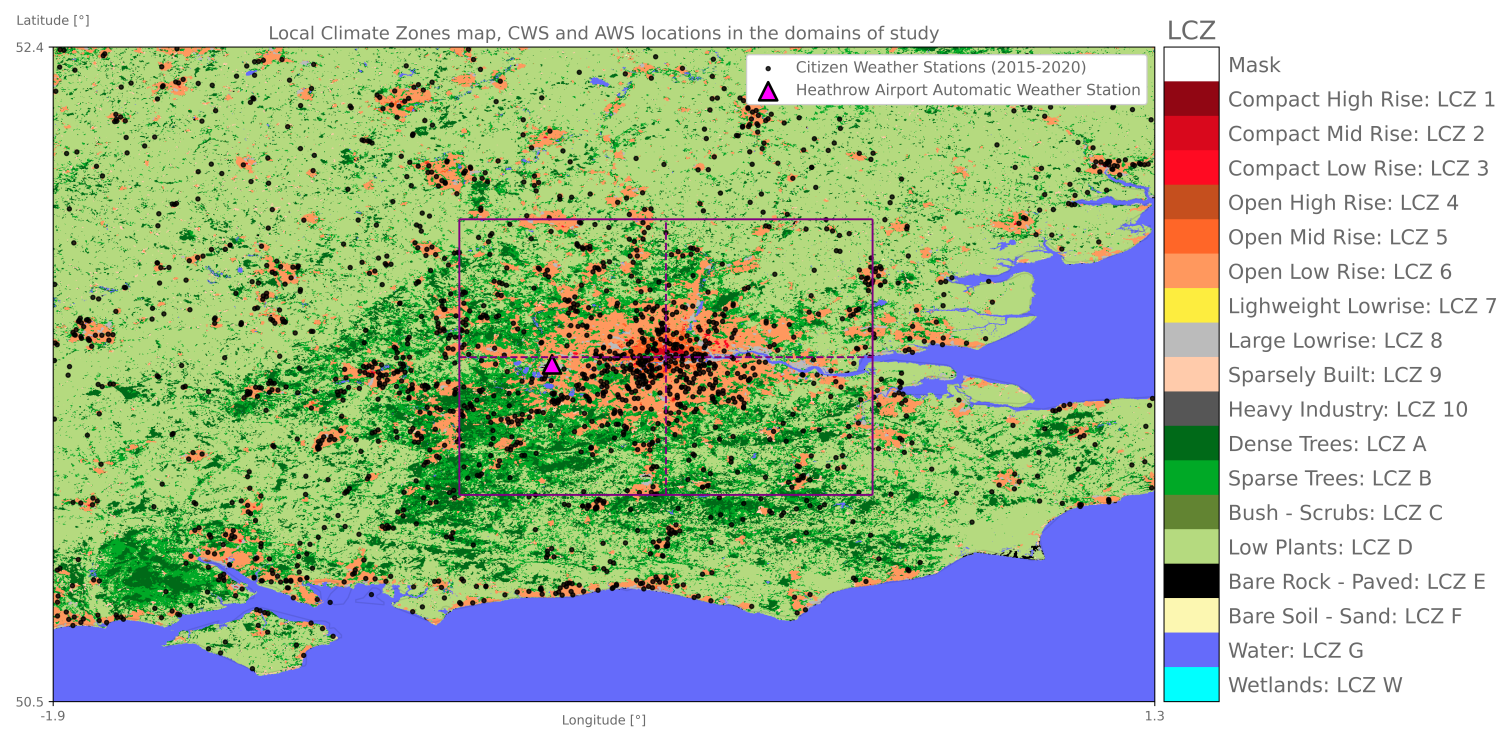

Figure 1: Map of Local Climate Zones (LCZ) in the larger domain of study (Domain 1). The smaller domain (Domain 2) is shown in purple with dashed lines representing the separation between four geographical quadrants for the UHA analysis Grey dots represent the location of quality-checked Netatmo Citizen Weather Stations (CWS) available within the time period from year 2015 to 2020. The Heathrow Airport MetOffice automatic weather station location is shown in fuchsia. LCZ source: Demuzere et al. (2019)

adaptation and mitigation strategies in cities. In London, England, CWS density has continuously been growing over recent years and temperatures have not changed over recent decades (1950-2019; Bassett et al. (2021)). This makes it a suitable place to study urban heat heterogeneities and horizontal advection. This study thus tries to demonstrate how CWS can help urban heat advection studies, by capturing complex dynamical and physical processes in urban environments. This could further help improve future urban planning and design. Therefore, in this study we: (i) build a 6-year quasi-climatology of near-surface air temperature, from 2015 to 2020, by acquiring, quality-checking and filtering all CWS present in a large domain covering southeast England and the Greater London area; (ii) use this quasi-climatology to look at the seasonal heterogeneity of urban heat in the domain and relate it to the locations of the CWS and the underlying LCZ land-use/land-cover; in order to (iii) define an appropriate domain to study and quantify the amount of UHA measured by CWS in each LCZ over the Greater London area in different seasons, and depending on prevailing wind speed and direction. This study is the first study to investigate UHA and urban heat heterogeneities among different LCZ using CWS in Greater London.

\section{Methodology}

\subsection{Study Area and Period}

Our study is focused on a large domain covering southeast England (see Figure 1), which includes the Greater London Authority administrative area and its surrounding urban areas. This large domain is host to 24 million inhabitants out of which 4 million are aged above 65 years old (for National Statistics, 2021). In the smaller domain, there are 13 million inhabitants and 1.7 million are older than 65 years old. This makes it a relevant case-study for urban temperature monitoring. We define our 6-year study period from 2015 to 2020 . 
We use two domains to perform two types of analyses at varying spatial and temporal scales (Figure 1). First, an extended domain (Domain 1) covering the Greater London area and the secondary urban nuclei in all directions - extending from $1.9^{\circ} \mathrm{W}$ to $1.3^{\circ} \mathrm{E}$ and $50.5^{\circ} \mathrm{N}$ to $52.4^{\circ} \mathrm{N}$ - is used for the data collection and for studying the regional climate to define a second domain used to study the UHA. This analysis is provided in Supplementary Information 5.4. Domain 2 is centered on $0.12{ }^{\circ} \mathrm{W}$ and $51.5^{\circ} \mathrm{N}$, close to Trafalgar Square, and extends by $0.6^{\circ}$ in west and east directions and by $0.5^{\circ}$ in north and south directions (Figure 1). An in-depth study on the influence and seasonality of prevailing winds on UHA is performed within Domain 2. To study hourly UHA, the domain is divided in four quadrants - North-East (NE), North-West (NW), South-West (SW), and South-East (NE) (see Section 2.3 for the definition) - following Heaviside et al. (2015) and Bassett et al. (2016). All the study is performed using a clipped part of the European Local Climate Zones (LCZ) map by Demuzere et al. (2019) (see Supplementary Information 5.1 for more information on LCZ).

\subsection{Data Collection, Filtering and Normalization}

In this study, two types of weather stations are used: Netatmo CWS, used for acquiring crowd-sourced measurement of hourly near-surface air temperature, and the Heathrow official MIDAS monitoring station from the United Kingdom Met Office (Office, 2020), used for hourly observations of wind speed and direction (justifications for chosing the latter station are given below).

\subsubsection{Air Temperature Measurements: Netatmo Citizen Weather Stations}

Netatmo CWS consist of two cylindrical modules shaded and protected by a cylindrical aluminium shell. Both modules, consisting of an outdoor and an indoor module, measure air temperature and relative humidity. The indoor module additionally measures $\mathrm{CO}_{2}$ concentrations, air pressure and noise levels (Meier et al., 2017). We collected hourly data from all Netatmo stations within Domain 1 for the whole 6-year period by using the Getpublicdata and Getmeasure functions of the Netatmo company's (https://netatmo.com) API (https://dev.netatmo.com/). We quality-checked the measurements using CrowdQC v1.2.0 R package developed by Grassmann et al. (2018) and used in Napoly et al. (2018). We kept only CWS measurements passing the M4 quality-check level and where at least $80 \%$ of a year of the whole 6-year period was available, following Fenner, Daniel and Holtmann, Achim and Meier, Fred and Langer, Ines and Scherer, Dieter (2019). This resulted in a reduction of the CWS sample from 1783 potential ones to 884 in the Domain 1. 423 are located in the Domain2. More information on the quality-checking and the distribution of CWS among the domains and LCZs is given in Supplementary Section 5.3, Figures S2 to S3 and Tables S1 to S3. Besides, we normalize the temperature observations by height, following Potgieter et al. (2021), to get rid of the vertical thermal gradient. $0.0065{ }^{\circ} \mathrm{C}$ are hence summed to the observed temperatures per meter anomaly to the average height across the domain. The averaged elevation of each CWS obtained from the Shuttle Radar Topography Mission (SRTM) elevation product at $30 \mathrm{~m}$ horizontal resolution is $62.3 \mathrm{~m}$.

\subsubsection{Wind speed and direction: MIDAS Automatic Weather Stations}

We gathered measurements of wind speed and direction from the Heathrow Airport official Met Office automatic weather station (Office, 2020) to define hourly prevailing winds over the Greater London area. This station follows the World Meteorological Organization standards and offers measurements of averaged wind speed and direction at hourly time steps at $10 \mathrm{~m}$ above ground level (Sunter, 2021). Other stations in the Greater London area also capture wind data (eg. Kew Gardens or Northolt). We chose, however, to only use the Heathrow station for defining prevailing winds. In fact, the Heathrow station is located at a similar latitude to the center of the Greater London area and is sufficiently close to the urban area to be considered representative of winds affecting the Greater London area. It is also one of the only stations in the Greater London area that cover the whole period of interest. We hence acquired the wind data for the same 6-year period as the Netatmo data (2015 to 2020). We converted the wind speeds measurements from knots to meters per second by considering: $1 \mathrm{kt}=0.5144 \mathrm{~m} \cdot \mathrm{s}^{-1}$. 


\subsection{Wind regimes definition}

To study the impact of wind direction and speed on the seasonal intra-urban heterogeneity of air temperature we classify wind speed into four easily understood categories with bins of $3 \mathrm{~m} \cdot \mathrm{s}^{-1}$, namely: Calm or Light Breeze with positive wind speed below $3 \mathrm{~m} \cdot \mathrm{s}^{-1}$; Gentle to Moderate Breeze with wind speed from $3 \mathrm{~m} \cdot \mathrm{s}^{-1}$ to $6 \mathrm{~m} \cdot \mathrm{s}^{-1}$; Moderate to Fresh Breeze, from $6 \mathrm{~m} \cdot \mathrm{s}^{-1}$ to $9 \mathrm{~m} \cdot \mathrm{s}^{-1}$; and Strong Breeze with wind speed above $9 \mathrm{~m} \cdot \mathrm{s}^{-1}$. We chose the upper threshold of $9 \mathrm{~m} \cdot \mathrm{s}^{-1}$ and above since less than $0.5 \%$ of the winds within our 6-year period are at speeds higher than $12 \mathrm{~m} \cdot \mathrm{s}^{-1}$ (Figure 2) and because it is close to the $95^{\text {th }}$ percentile. Over the six years, the median speed is $3.60 \mathrm{~m} \cdot \mathrm{s}^{-1}$, the average speed is $4.2 \mathrm{~m} \cdot \mathrm{s}^{-1}$ and the maximum observed hourly wind speed is $18.5 \mathrm{~m} \cdot \mathrm{s}^{-1}$. $31.6 \%$ of the available hourly wind measurements are considered as Calm or Light Breeze, $48.59 \%$ as Gentle to Moderate Breeze, $16.19 \%$ as Moderate to Fresh Breeze and $3.63 \%$ as Strong Breeze. In general, the winds follow a log-normal distribution and our simplified classes therefore cover meaningful probabilistic distributions with the first two covering common events, whilst the second two focus on more extreme situations with different occurrence probabilities.

\subsection{Measuring urban temperatures and urban heat advection}

Since the majority of the CWS are located within urban built environments (Table S2), and since we cannot ascertain that CWS located in natural LCZs are not influenced by urban heat, we decided to focus on air temperature and daily temperature ranges instead of quantifying the urban heat island intensity. This idea follows the recommendations provided by Stewart (2011) and Stewart and Oke (2012), who argue that urban climate studies should focus more on the quantification of urban heat than on the urban heat island intensity (also see Martilli et al. (2020)).

To study the effect of wind speed and direction on the inter- and intra-LCZ heat heterogeneity, hourly values are used to avoid compensating effects that may occur, for example if the wind direction changes significantly within a 24 hour period. We define UHA as the air temperature anomaly measured by the CWS between an upwind and a downwind quadrant that is not related to the land-use land-cover and environmental differences between the two quadrants (see Equation 1). Our Domain 2 quadrants are defined by angles of 90 - increasing clockwise. Hence, for example, the North-Eastern and the South-Western quadrants are considered upwind and downwind, respectively, when winds are blowing from angles comprised between 0 . and 90 . We do not include hours when wind direction recently changed by filtering out hours when the wind direction is not blowing from the same quadrant for at least three hours - the first two hours are hence excluded. This threshold is subjectively fixed based on the distance from the center of each quadrant to the center of Domain 2 and the median wind speed over the 6 years. We also filter out hours with wind speed equal to 0 to avoid accounting for hours when no urban heat is advected. This reduced the amount of potential studied hours by $30 \%$ without importantly affecting the probabilistic distribution of wind regimes (see Supplementary Section 5.3).

Once this filtering is done, we test the statistical significance of measured UHA by CWS in two steps: first, we test how averaged winds generally affect each quadrant by testing with a one-tailed t-test of paired samples whether the averaged air temperature in these quadrants is significantly lower when located upwind than downwind - we call this difference $\Delta \mathrm{T}$; second, we test how prevailing winds are responsible for heat advection in the urban area by testing with a one-tailed t-test of paired samples whether the same quadrant when located upwind or downwind significantly loses or gains heat, respectively, in comparison to the opposite quadrant - we call this $\triangle$ UHA (Equation 2). To measure UHA (and hence $\triangle \mathrm{UHA}$ ) we consider the strategies adopted by Heaviside et al. (2015) and Bassett et al. (2016) to measure the hourly advected heat under different wind regimes. Our method diverges from theirs as Heaviside et al. (2015) used a non-urban and an urban climate simulation to quantify the expected averaged urban heat in each quadrant, and Bassett et al. (2016) normalized the observed averaged urban heat of each quadrant by their urban fraction. Here, we assume that similar LCZs are expected to have a similar impact on the local urban heat anomaly. To quantify the two-dimensional advected heat at each CWS location per LCZ $\left(\overline{U H A}_{C W S_{L C Z^{x}}^{i, \theta d w}}\right)$, we thus subtract the averaged temper- 

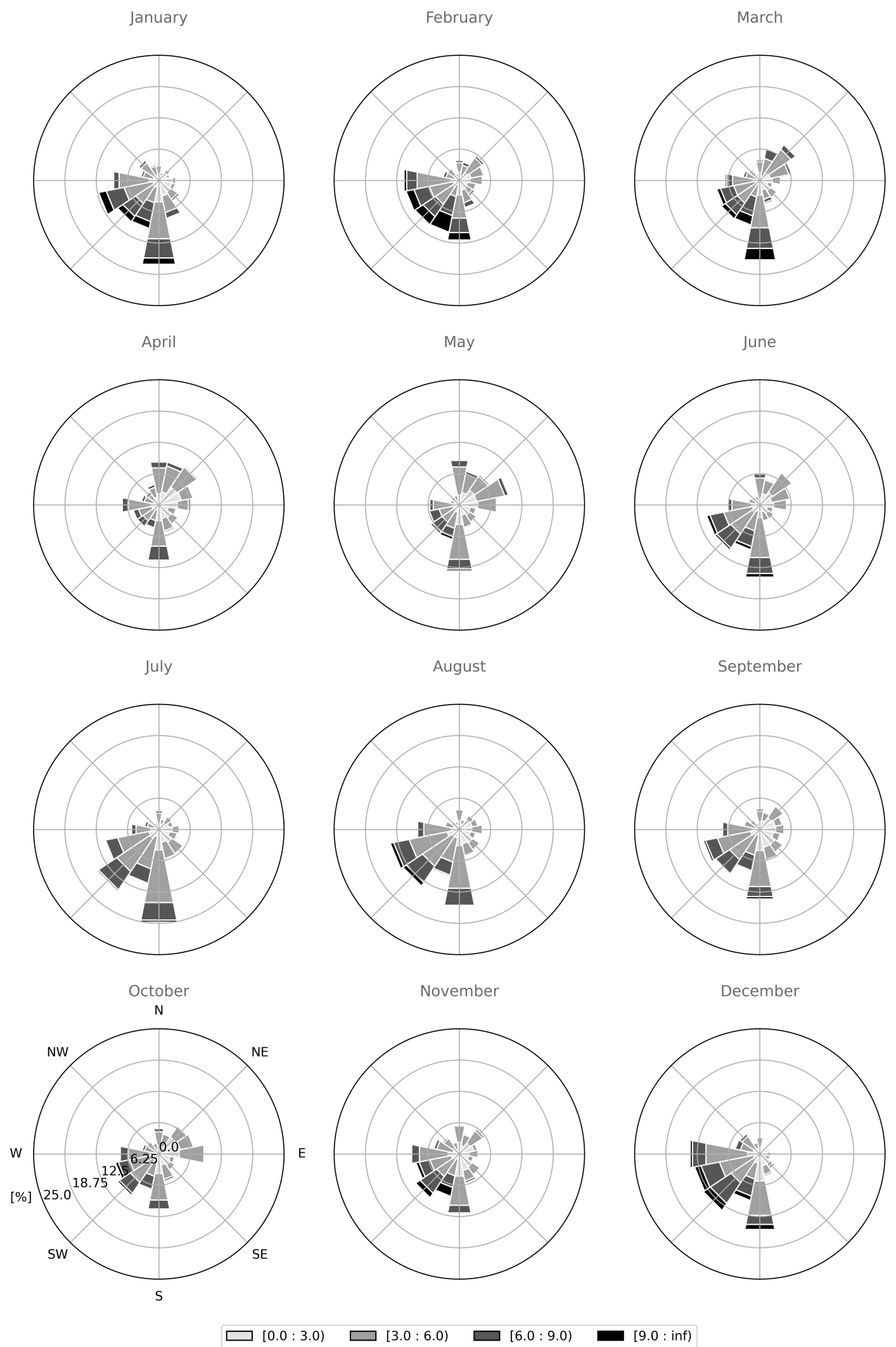

Figure 2: Monthly wind roses of observed hourly wind speed (in meters per second) and direction at Heathrow Airport from 2015 to 2020. Each bin cofresponds to a separate wind regime class. 
ature of all CWS located in a certain LCZ from the upwind quadrant $\left(\bar{T}_{\forall C W S} \in L C Z^{x} \wedge \theta^{u w}\right)$ to each CWS of the same LCZ located in the downwind quadrant $\left(\bar{T}_{C W S_{L C Z x}^{i, \theta d w}}\right.$; see Equation 1). To ascertain that the differences in urban heat are not related to the local land surface characteristics responsible of the averaged UHI, nor to the averaged UHA related to the location of the CWS at which advection is measured, the time-mean averaged temperature per CWS $\left(\bar{T}_{\forall C W S}\right)$ is subtracted to their respective CWS prior to calculating the UHA. This way we look at the additional UHA related to each prevailling wind event rather than to the averaged UHA and UHI at the location. As Heaviside et al. (2015) note, "this assumption is reasonable if statistical distributions of meteorological quantities are independent of wind direction". According to the method given above, we hence have three metrics of importance in the analysis: UHA, $\Delta$ UHA and $\Delta \mathrm{T}$. They are calculated as such:

$$
\overline{U H A}_{C W S_{L C Z^{x}}^{i, \theta d w}}=\left(\bar{T}_{C W S_{L C Z^{x}}^{i, \theta d w}}-\bar{T}_{\forall C W S}\right)-\left(\bar{T}_{\forall C W S} \in L C Z^{x} \wedge \theta^{u w}-\bar{T}_{\forall C W S}\right)
$$

Where $\overline{U H A}$ is the averaged advected heat at $i^{\text {th }} \mathrm{CWS}$, located in $x \mathrm{LCZ}$ in the downwind quadrant $\theta^{u w}$ during certain prevailing wind conditions. $\bar{T}_{\forall C W S}$ is the time-mean averaged temperature of each CWS located in $x$ LCZ of the smaller domain, while $\bar{T}_{\forall C W S} \in L C Z^{x} \wedge \theta^{u w}$ is the averaged temperature of all CWS located in $x$ LCZ and in the upwind quadrant $\theta^{u w}$. All averaged temperatures $\bar{T}$ are normalized by the height of the CWS.

$$
\Delta \overline{U H A}_{C W S_{L C Z^{x}}^{i, \theta q}}=\overline{U H A}_{C W S_{L C Z^{x}}^{i, \theta q}}^{\tau^{u w}}-\overline{U H A}_{C W S_{L C Z^{x}}^{i, \theta q}}^{\tau^{d w}}
$$

Where $\Delta \overline{U H A}_{\forall} C W S^{\theta^{q}}$ is the difference of time-averaged advected heat UHA calculated following Equation 1 in all CWS located in $q^{\text {th }}$ quadrant $\theta$ per $i^{\text {th }}$ LCZ during times $\tau$ when located upwind (uw) or downwind $(d w)$ in comparison to the opposite quadrant.

$$
\Delta \bar{T}_{C W S_{L C Z^{x}}^{i, \theta q}}=\bar{T}_{C W S_{L C Z^{x}}^{i, \theta q}}^{\tau^{d w}}-\bar{T}_{C W S_{L C Z^{x}}^{i, \theta q}}^{\tau^{u w}}
$$

Where $\Delta \bar{T}_{C W S_{L C Z^{x}}^{i, \theta q}}$ is the difference of time-averaged temperatures measured in all CWS located in $q^{t h}$ quadrant $\theta$ per $i^{\text {th }}$ LCZ during times $\tau$ when located upwind (uw) or downwind $(d w)$.

This way, we make sure to define the inter- and intra-LCZ differences in terms of heat advection. Since LCZs in London follow a relatively uniform concentric distribution, we are able to see where UHA is most important between the urban center and the suburbs.

\section{Results}

\subsection{Quasi-climatology in the large domain (Domain 1)}

The results of this analysis are given in Supplementary Information 5.4. In short, we find that there is a great level of spatial heterogeneity in the quasi-climatology of temperatures and daily temperature ranges that is not explained by the spatial heterogeneity of percentages of available measurements (Pearson's $\mathrm{r}^{2}<0.05$ ). A consistent monthly urban heat island by about $\sim 1.0{ }^{\circ} \mathrm{C}$ to $\sim 2.0{ }^{\circ} \mathrm{C}$ over the Greater London area appears, prevailing in autumn and winter months. Measurements captured by CWS closer to the southern shores are relatively hotter than inland ones during winter and cooler during summer. Daily temperature ranges are systematically found lower in the denser parts of the Greater London area and on the southern shores. This shows the ability of CWS to capture spatial variability of local climates and defends the choice of Domain 2 for the subsequent UHA analysis (Figure S1). We also find that CWS located in more compact and built-up LCZ are hotter on average and that they have lower daily temperature ranges throughout the year. 
Table 1: Averaged advected heat anomalies difference $\triangle \mathrm{UHA}$ in degrees Celsius $\left({ }^{\circ} \mathrm{C}\right)$ per LCZ between same CWS in each quadrant when located upwind or downwind (Upwind - Downwind). Significance is given by the p-value from a one-sided dependent t-test with unequal variance. Statistically significant values at $10 \%$ are put in bold.

\begin{tabular}{|c|c|c|c|c|c|c|c|c|}
\hline \multirow[t]{2}{*}{ LCZ } & \multicolumn{2}{|c|}{ North-East } & \multicolumn{2}{|c|}{ South-East } & \multicolumn{2}{|c|}{ South-West } & \multicolumn{2}{|c|}{ North-West } \\
\hline & $\triangle$ UHA & $\begin{array}{l}\text { p- } \\
\text { value }\end{array}$ & $\Delta \mathbf{U H A}$ & $\begin{array}{l}\mathrm{p}- \\
\text { value }\end{array}$ & $\triangle$ UHA & $\begin{array}{l}\text { p- } \\
\text { value }\end{array}$ & $\triangle \mathbf{U H A}$ & $\begin{array}{l}\text { p- } \\
\text { value }\end{array}$ \\
\hline Compact Mid Rise: LCZ 2 & $\overline{1.04 \mathrm{E}^{-3}}$ & 0.50 & -0.23 & - & -0.43 & - & -0.03 & - \\
\hline Open Mid Rise: LCZ 5 & -0.07 & 0.25 & -0.23 & - & -0.10 & $2.98 \mathrm{E}^{-}$ & -0.06 & 0.19 \\
\hline Open I & -0.26 & $1.22 \mathrm{E}^{-}$ & -0.16 & $9.60 \mathrm{E}^{-}$ & ${ }^{3}-0.20$ & $1.84 \mathrm{E}^{-}$ & ${ }^{2}-0.12$ & $5.44 \mathrm{E}^{-1}$ \\
\hline Large Lowrise: LCZ 8 & -0.41 & - & -0.22 & 0.22 & -0.21 & 0.13 & -0.35 & - \\
\hline Sparsely Built: LCZ 9 & -0.44 & - & -0.20 & $8.54 \mathrm{E}^{-}$ & -0.02 & 0.45 & - & - \\
\hline Dense Trees: LCZ A & - & - & -0.49 & 0.08 & -0.12 & 0.02 & -0.26 & 0.09 \\
\hline CZ B & -0.34 & 0 . & -0.15 & 0.04 & -0.07 & 0.07 & -0.15 & $6.78 \mathrm{E}^{-3}$ \\
\hline Low Plants: LCZ D & -0.27 & 0.04 & -0.20 & 0.17 & -0.18 & - & -0.26 & 0.04 \\
\hline
\end{tabular}

\subsection{Influence of wind regime on urban heat heterogeneity and heat advec- tion}

We find that winds have a noticeable impact on the temperature anomalies between similar LCZ located upwind or downwind. We calculate a cross-CWS time-mean positive UHA of $0.22{ }^{\circ} \mathrm{C}$ over the 6-year period (2015-2020; Figure 3). Positive averaged UHA per CWS are usually between $0{ }^{\circ} \mathrm{C}$ and $1.0{ }^{\circ} \mathrm{C}$ and can reach up to $\sim 2.0{ }^{\circ} \mathrm{C}$. Negative averaged UHA rarely go below $\sim-1.0^{\circ} \mathrm{C}$, apart from the downwind stations in compact mid-rise (LCZ 2) and large-lowrise (LCZ 8) during south- and north-easterly, and south-westerly conditions, respectively. High degrees of intra-LCZ variability are also observed, meaning that while the median anomaly can be positive, certain CWS in an area with similar LULC will measure a negative anomaly. Highest degrees of intra-LCZ variability are observed in open low-rise (LCZ 6), and more natural LCZs, like sparsely built (LCZ 9), dense trees (LCZ A), sparse trees (LCZ B) and low vegetation (LCZ D).

On average, CWS located in the same quadrant will experience a positive $\triangle$ UHA anomaly of $0.21^{\circ} \mathrm{C}$ when located downwind than upwind for each wind regime (Table 1 ). When looking at intraLCZ differences significant at $10 \%$ (Table 1 in bold), CWS located in dense trees (LCZ A) from the south-western quadrant will observe a maximum $\triangle$ UHA of $0.49{ }^{\circ} \mathrm{C}$ while the minimum of $0.07{ }^{\circ} \mathrm{C}$ is observed for CWS located in sparse trees (LCZ B) of the same quadrant. A clear signal in heat advection among CWS located in natural LCZs is thus perceived. In urban LCZ, $\triangle$ UHA can reach $0.26{ }^{\circ} \mathrm{C}$ in open low-rise ( $\mathrm{LCZ} 6$ ). In addition, the inter-season and inter-LCZ variability of the anomaly appears to be more related to the orientation of the prevailing winds and to their speeds rather than to the seasons (Figure S7). This is also observable when looking at the temperature anomaly $\Delta \mathrm{T}$ of the same CWS in each quadrant when located downwind or upwind (Table 2). In fact, under northern wind conditions, CWS located in the Northern quadrants will be significantly cooler than during Southern prevailing winds at $10 \%$ (Table 2 in bold). Noticeably, the opposite mostly happens in southern quadrants when subject to southern winds, but with no statistical significance. Only CWS of the south-western quadrant located in open low-rise (LCZ 6) and in sparse trees (LCZ B) were found to also be significantly cooler when located upwind.

Stronger winds are not related to higher heat transport. On the contrary, they tend to reduce the amount of advected heat in certain LCZs, like open mid-rises (LCZ 5) during south-westerly conditions (Figure 3 and Figure S7). In addition, the higher the wind speed, the lower the inter-CWS variability of UHA and the more it converges towards the averaged UHA (Figure 4, second row). Openly built urban and natural LCZs appear to be similarly affected by UHA (Figure 3). CWS located in compact mid-rises (LCZ 2) or large-lowrise (LCZ 8), mostly located in the center of Domain 2, show large fluctuations of UHA from one wind condition to another (Figure 3). In contrast, UHA in more open 
Table 2: Averaged temperature difference $\Delta \mathrm{T}$ in degree Celsius $\left({ }^{\circ} \mathrm{C}\right)$ per Local Climate Zone between same citizen weather stations in each quadrants when located upwind or downwind (Upwind - Downwind). Significance is given by the p-value from a one-sided dependent t-test with unequal variance. Statistically significant values at $10 \%$ are put in bold.

\begin{tabular}{|c|c|c|c|c|c|c|c|c|}
\hline \multirow[t]{2}{*}{ LCZ } & \multicolumn{2}{|c|}{ North-East } & \multicolumn{2}{|c|}{ South-East } & \multicolumn{2}{|c|}{ South-West } & \multicolumn{2}{|c|}{ North-West } \\
\hline & $\Delta \mathbf{T}$ & $\begin{array}{l}p- \\
\text { value }\end{array}$ & $\Delta \mathbf{T}$ & $\begin{array}{l}\text { p- } \\
\text { value }\end{array}$ & $\Delta \mathbf{T}$ & $\begin{array}{l}\text { p- } \\
\text { value }\end{array}$ & $\Delta \mathbf{T}$ & $\begin{array}{l}\text { p- } \\
\text { value }\end{array}$ \\
\hline Compact Mid Rise: LCZ 2 & -2.0 & $1.00 \mathbf{E}^{-}$ & -0.37 & - & 0.52 & - & -1.80 & - \\
\hline Compact Low Rise: LCZ 3 & -3.16 & - & - & - & - & - & - & - \\
\hline Open Mid Rise: LCZ 5 & -2.40 & $8.01 E^{-6}$ & -0.37 & - & 0.51 & 0.97 & -1.88 & $2.41 \mathrm{E}^{-\phi}$ \\
\hline Open Low Rise: LCZ 6 & -1.87 & $6.68 \mathrm{E}^{-1}$ & ${ }^{8}-0.16$ & 0.01 & 0.53 & 0.99 & -2.10 & $8.69 \mathrm{E}^{-5}$ \\
\hline Large Lowrise: LCZ 8 & -4.11 & - & -0.07 & 0.44 & 0.58 & 0.94 & -2.05 & - \\
\hline Sparsely Built: LCZ 9 & -2.13 & - & -0.13 & 0.31 & 0.17 & 0.57 & - & - \\
\hline Dense Trees: LCZ A & - & - & -0.09 & 0.25 & $3.60 \mathrm{E}^{-3}$ & 0.50 & -2.34 & 0.03 \\
\hline Sparse Trees: LCZ B & -2.47 & 0.06 & -0.56 & 0.09 & 0.76 & 0.99 & -2.39 & $1.48 \mathrm{E}^{-\tau}$ \\
\hline Low Plants: LCZ D & -2.01 & 0.03 & -0.12 & 0.40 & 0.60 & - & -2.52 & 0.01 \\
\hline
\end{tabular}

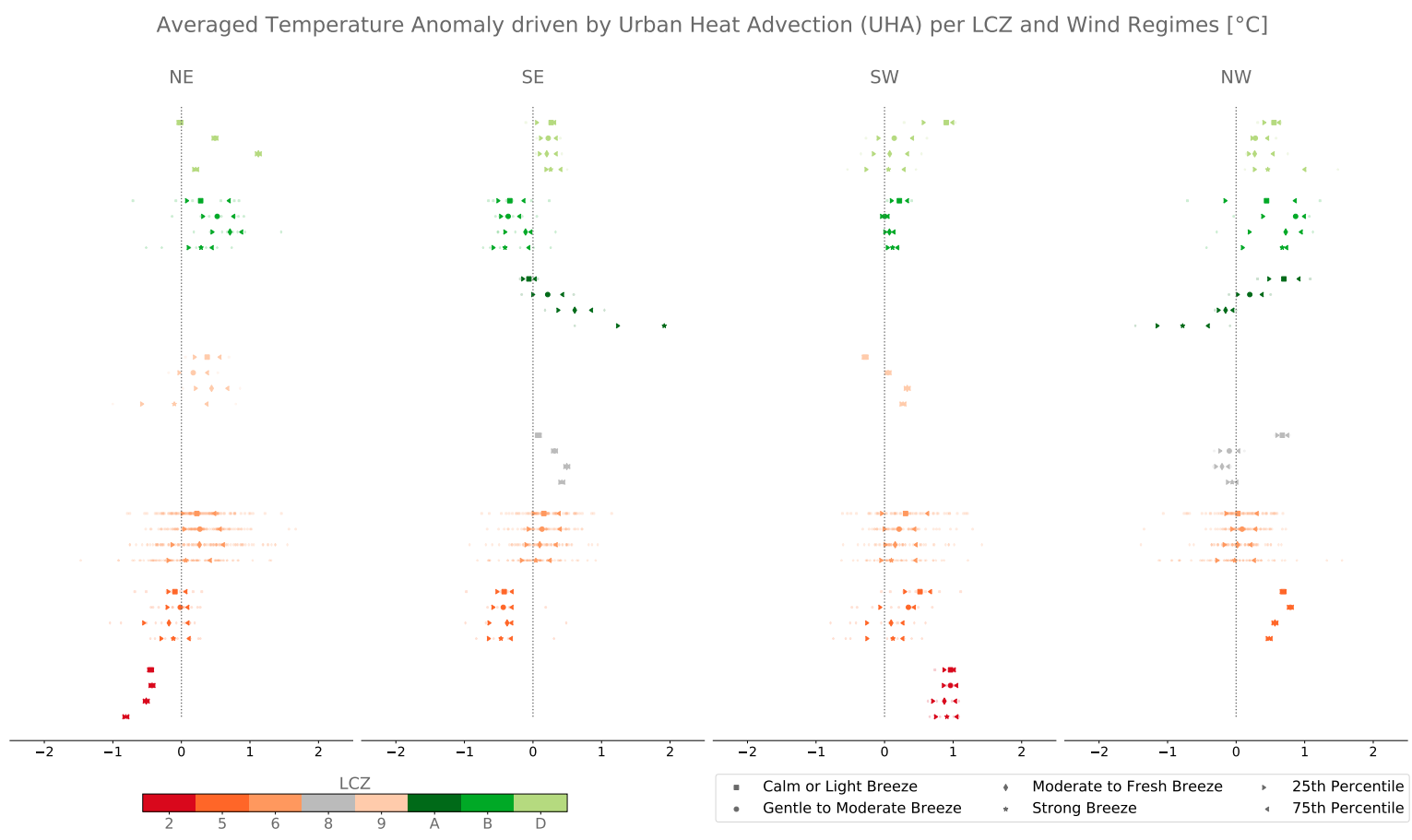

Figure 3: 6-year averaged (2015-2020) hourly urban heat advection (UHA) per downwind citizen weather station (CWS) in each Local Climate Zone and upwind prevailing winds. Large markers represent the cross-CWS median of the averaged UHA and triangle whiskers represent the $25^{t h}$ and $75^{\text {th }}$ percentiles. 


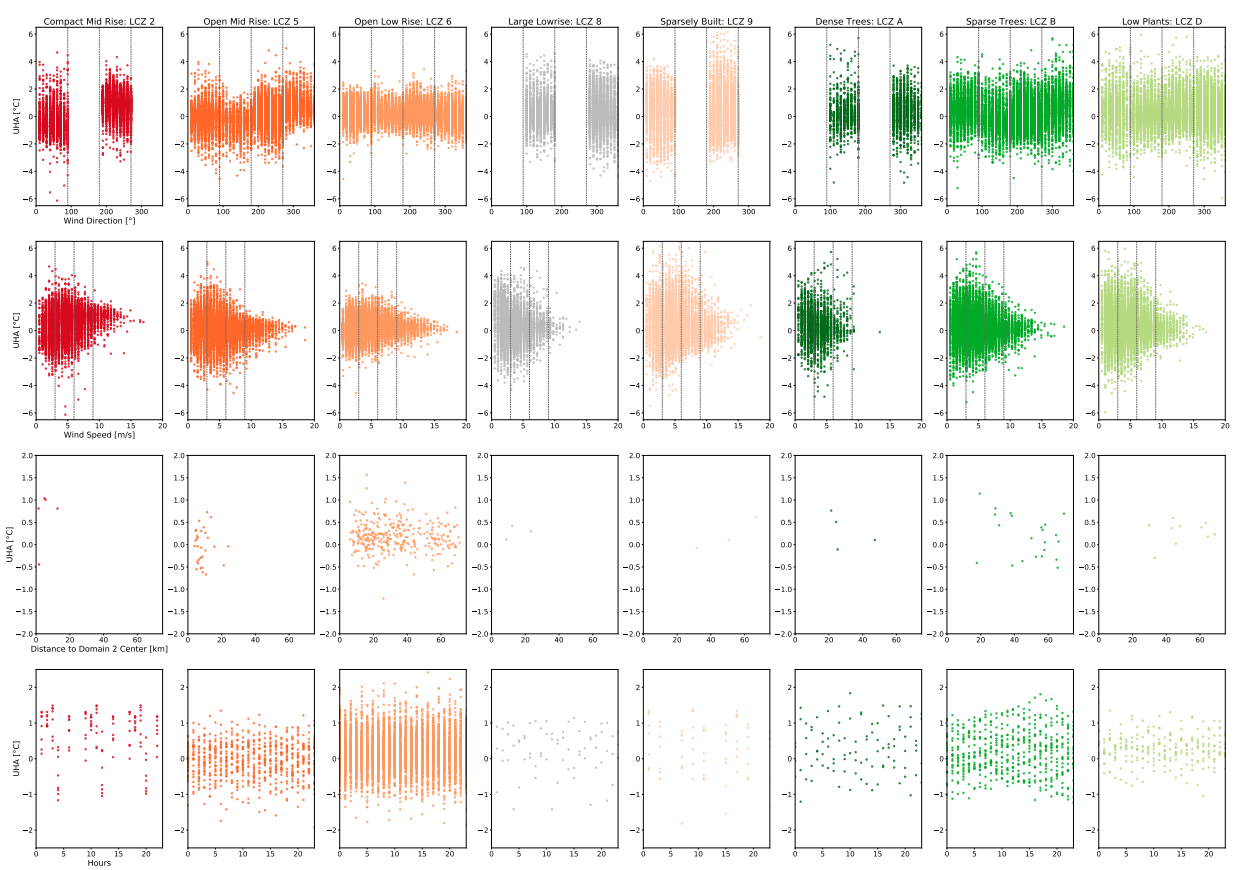

Figure 4: Hourly cross-CWS averaged UHA against wind speed and orientation (first two rows above; dotted lines represent the limits for their respective classes), time-mean UHA per CWS against distance to the center of Domain 2 (third row) and 6-year-hourly-mean UHA per CWS (fourth row). Each row is subdivided by LCZ to allow for inter- and intra-LCZ comparison. 


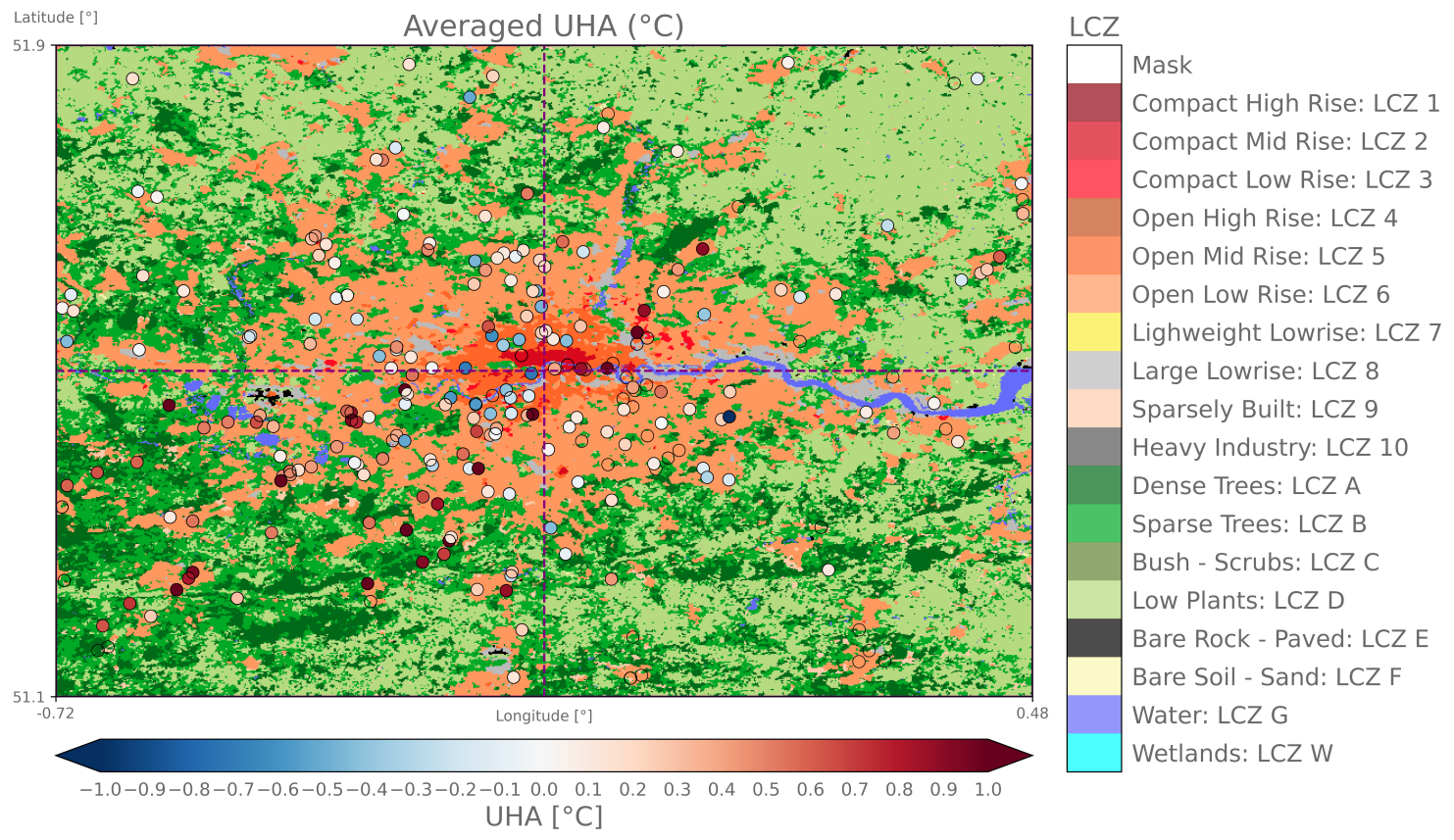

Figure 5: 6-year averaged urban heat advection per citizen weather stations overlaid on the Local Climate Zones map of the Greater London area (Domain 2). Dashed purple lines represent the quadrants borders. CWS where no UHA could be measured are made transparent.

LCZs, like open mid- or low-rises (LCZ 5 and LCZ 6, respectively) are similar for all wind regimes. Importantly, negative UHA values are found, suggesting that UHA does not happen homogeneously across the downwind quadrants. By looking at the temporal evolution of UHA, we did not find a systematic signal showing that UHA is more pronounced during certain hours (Figure 4, fourth row). Trying to relate UHA to the distance to the city center and to the wind orientation was inconclusive because of the great inter-CWS variability in UHA. Indeed, CWS close to the urban center, mostly composed of compact and open mid-rises (LCZ 2 and LCZ 5), and located in the south-western corner show a negative 6-year averaged UHA (Figure 5). UHA appears to be more pronounced in peripheric areas and along the south-west/north-east transect. Mostly positive UHA are found in each quadrant although the inter-CWS variability varies greatly from one quadrant to another. For instance, lowest variability in averaged UHA is found in the north-western quadrant, while higher levels of inter-CWS variability are found in the south-western and north-eastern quadrants.

\section{Discussion and Conclusions}

In this paper, we show that crowdsourced CWS can help with monitoring and studying urban temperatures for recent years in a variety of urban environments, supporting a number of previous studies (e.g., Meier et al. (2015, 2017); Chapman et al. (2017); Fenner et al. (2017); Napoly et al. (2018); Fenner, Daniel and Holtmann, Achim and Meier, Fred and Langer, Ines and Scherer, Dieter (2019); Droste et al. (2020); de Vos et al. (2020); Venter et al. (2020); Varentsov et al. (2020); Benjamin et al. (2021); Potgieter et al. (2021); Venter et al. (2021)). In our study, quality-checked CWS are sensitive to seasonal changes and local climate features in the south-eastern parts of England, like the coastal climate in the South, or the heterogeneity of the urban environments in the Greater London area in terms of Local Climate Zones (LCZ). By focusing on a 6-year period ranging from 2015 to 2020, we showed a marked higher urban heat in the Greater London area by $1.0^{\circ} \mathrm{C}$ to $1.5^{\circ} \mathrm{C}$ using $\mathrm{CWS}$. 
This was also described by Chandler (1965) for the 1921-1950 period with an averaged difference of $1.1{ }^{\circ} \mathrm{C}$ and $0.55{ }^{\circ} \mathrm{C}$ between surrounding country and suburbs, respectively, and the central districts. This confirms that London's urban heat island effect has not importantly changed over recent decades (Bassett et al., 2021), even if it has been subject to recent rapid changes in temperatures related to climate change (see IPCC report; Pachauri et al. (2014)). Urban heat is however related to landuse land-cover, with more central compact mid rises (LCZ 2) always revealing an increased monthly average hourly temperature by up to $\sim 1.5^{\circ} \mathrm{C}$ throughout the year compared to more open LCZs, and a smaller daily temperature range. The urban heat magnitude monitored by the CWS is in line with recent observational and modelling studies, although most of them focused on summer months only (Mavrogianni et al., 2011; Grawe et al., 2013; Chapman et al., 2017; Benjamin et al., 2021). Intra-urban heterogeneity using LCZ was also demonstrated in previous studies from Fenner et al. (2017); Benjamin et al. (2021); Potgieter et al. (2021) and Varentsov et al. (2021). Similar differences between more compact LCZs and more open or natural ones were found in Berlin for the year 2015 only (Fenner et al., 2017). Nonetheless, since cities usually have a denser urban center, it is difficult to attribute which part of the positive anomaly is related to the urban typology rather than to the central location subject to heat advection from the surrounding environments. Varentsov et al. (2021) found in Moscow, Russia, that meso-scale urban surroundings are about as equally important as local-scale surroundings for explaining the spatial heterogeneity of urban heat. Potgieter et al. (2021) emphasized the latter point by discussing why more densely built high-rises in the city of Sydney, Australia, may show cooler minima than other urban environments in a coastal climate.

In our study, we showed that prevailing winds don't explain differences in temperatures at the same CWS location, but still drive urban heat advection (UHA) in Greater London. The latter is significantly captured by CWS. On average, UHA deprives London's central neighborhoods from urban heat and transfer it to more suburban areas. This advection is around $0.22{ }^{\circ} \mathrm{C}$ on average in all Greater London neighbourhoods for all downwind wind conditions during our 6-year period (2015-2020). UHA hence deprives upwind quadrants by an additional $\sim 10 \%$ of the advected cooler air from the rural lands and causes an important spatio-temporal variability of urban heat. We found, for example, high degrees of intra-LCZ variability in UHA - eg., in open mid- or low-rise (LCZ 5 and LCZ 6) locations. Natural areas within London are also subject to urban heat transport, which could reduce their value as urban cool spots. In fact, depending on the wind conditions and the LCZ in which CWS are located, UHA can reach up to $\sim 2.5^{\circ} \mathrm{C}$ on average with values usually below $1.0^{\circ} \mathrm{C}$ - being in line with previous studies on UHA in Birmingham by Bassett et al. (2016) and Heaviside et al. (2015). At certain hours in our 6-year period, we could even measure positive and negative UHA of up to $\sim 6.0^{\circ} \mathrm{C}$. This variability in hourly UHA tended to be reduced with higher wind speeds (eg., above $9 \mathrm{~m} \cdot \mathrm{s}^{-1}$ ). It can be explained by the heterogeneous and complex diffusion of airflows within the complex urban three-dimensional environment as illustrated in Figure 6 (Hall et al., 1997; Grimmond and Oke, 1999; Oke et al., 2017). Such results actually suggest that although general meteorological circulations can generally explain where heat will be transported, more local micro-climatic phenomena are of equal importance in explaining the spatio-temporal variability of UHA. The latter also explains why both negative and positive UHA can be measured at the same time by CWS in downwind quadrants. More in-depth studies using machine learning and trying to relate other surface earth observations to airtemperature variations should be tried to explain the variability of urban heat, e.g., Venter et al. (2021).

Despite the novelty of the results we show, our study suffers from certain limitations. For instance, we: (i) used partly arbitrary wind regimes classes derived from the Beaufort scale and quantiles of wind speeds that could be refined via more quantitative analysis; (ii) considered quadrants with very few CWS to still be representative of the heat advection because of the restrictions we impose in the data selection; (iii) only used one representative official weather station (Heathrow Airport) to classify prevailing winds over the area of interest and (iv) did not study the vertical winds and the related heat advection. Complex dynamics and physics play a role in the dispersion of the urban heat plume (Oke, 1982; Souch and Grimmond, 2006; Heaviside et al., 2015; Oke et al., 2017) and will require future observational and modelling studies to better understand the spatio-temporal patterns of UHA. 


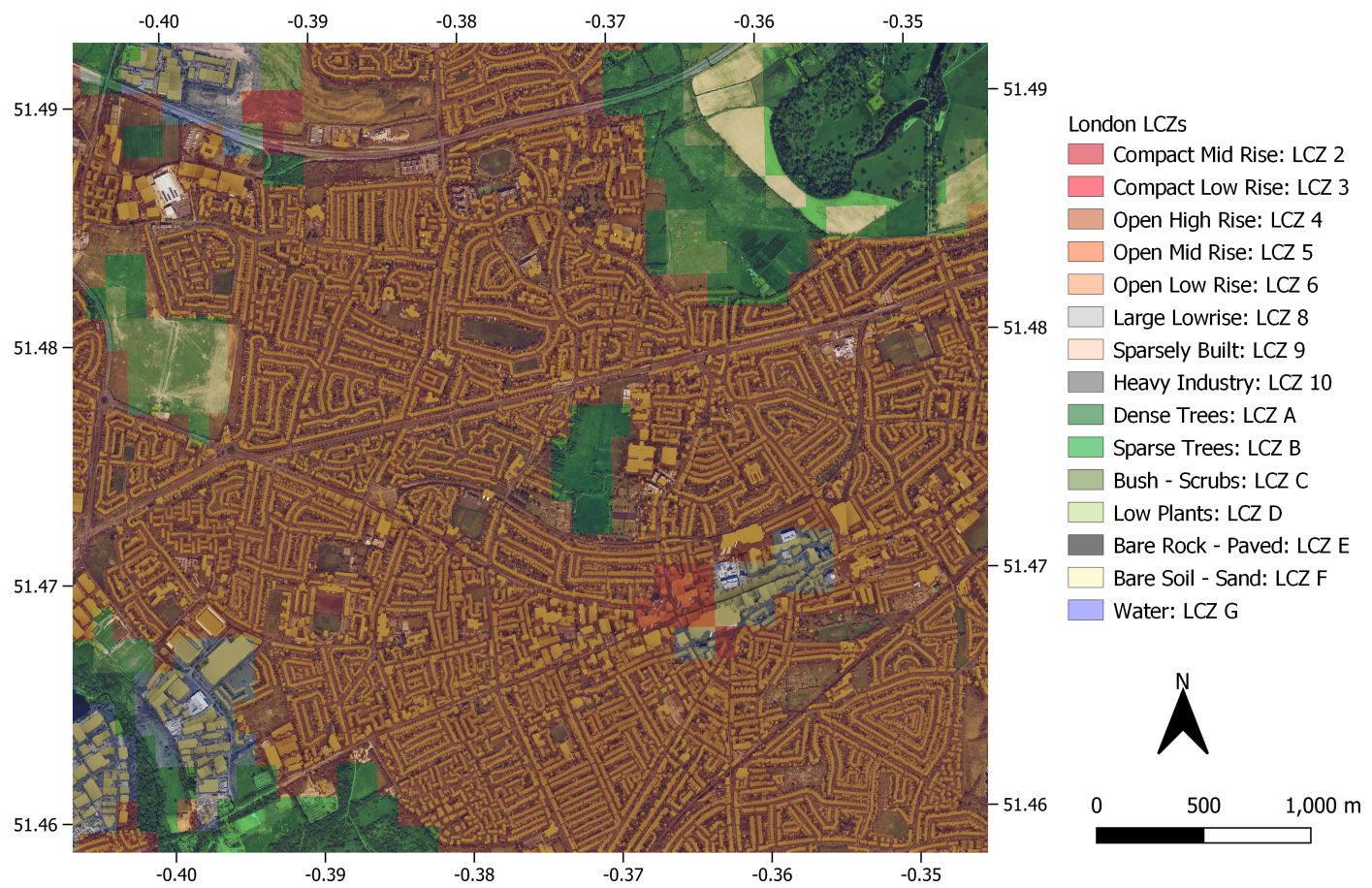

Figure 6: Example of the built-up environment's three-dimensional complexity in the city of London overlaid on the European LCZ map by Demuzere et al. (2019). Coordinates are in longitude and latitude. 
Nonetheless, adaptive measures for London's neighborhoods could already integrate such results in their design. Indeed, urban planners, architects, and environmental design engineers can now benefit from high spatial resolution climate data derived from CWS. This can be considered, for example, in designs for greenspace, street shading and ventilation, surface materials, and building design and heat adaptation (Goodess et al., 2021). Innovative tools, like the ones developed by Varentsov et al. (2020) can also help monitoring places at higher chances of heat stress in real-time using CWS data. As such, urban planners could use these tools to consider higher risks of heat exposure based on prevailing winds and the related UHA using CWS. In fact, adaptative and mitigative strategies should be tailored according to the local climates' spatio-temporal variability to allow for both a reduction of heat-related pubic health risks and for the design of more intelligent low-energy buildings. This encourages for the densification of CWS networks and future research to be done using them.

\subsection{Acknowledgement}

CH is supported by a NERC fellowship (NE/R01440X/1) and acknowledges funding from the Wellcome HEROIC project $(216035 / \mathrm{Z} / 19 / \mathrm{Z})$, which also funds OB and CS. 


\section{Supplements}

\subsection{Local Climate Zones - LCZ}

Local Climate Zones (LCZ) are universal and standardized classes of a land-use/land-cover classification that provide urban morphological, thermal and radiative parameters, useful for urban climate studies (Stewart and Oke, 2012; Ching et al., 2018). In fact, they decompose the urban environments into 17 classes (10 urban and 7 natural) representative of surface information at a scale of hundreds of meters to few kilometers, and that are expected to have an important impact on the local climate (Stewart and Oke, 2012). Since Bechtel et al. (2015) proposed a strategy to map LCZ out of satellite earth observations, the World Urban Database and Access Portal Tool (WUDAPT, Ching et al. (2018)) has formalized this framework and worked on its development across various cities and continents (eg., Bechtel et al. (2017); Brousse et al. (2019, 2020); Demuzere et al. (2019, 2020); Ren et al. (2019)).

The LCZ map of London obtained from the European LCZ map Demuzere et al. (2019) indicates that most of London is classified as open low-rise (LCZ 6) (Figure 1). LCZ 6 usually consists of open and vegetated residential areas. The center of the city is mostly composed of compact and open mid-rise categories (LCZ 2 and LCZ 5). Industrial and commercial areas, classified as large low-rise (LCZ 8), tend to be located along the River Thames. In general, in Greater London, urbanized land follows a concentric pattern, with denser parts located at the center and more open areas located further from the centre. The proportion of each urban LCZ in the four quadrants of Domain 2 is rather homogeneous (Table S1), with the predominant LCZ 6 comprising of $\sim 20.7 \%$ to $\sim 28.3 \%$ of each quadrant. There is a noticeable presence of LCZ 5 and LCZ 8 in each quadrant, representing $\sim 1.2 \%$ to $\sim 2.8 \%$ and $\sim 1.3 \%$ to $\sim 2.2 \%$, respectively. LCZ 2 and LCZ 3 are more present in the NorthEastern corner, comprising $\sim 0.6 \%$ and $\sim 0.3 \%$ of the land cover, respectively. The rest of Domain 2 is mostly composed of vegetated natural LCZs ( LCZ A, LCZ B, LCZ C) with a negligible presence of mineral or natural LCZs (LCZ E and LCZ F).

Table S1: Percentages of Local Climate Zones (LCZ) composing each quadrant of Domain 2

\begin{tabular}{|l|l|l|l|l|}
\hline LCZ & NE & NW & SE & SW \\
\hline Compact Mid Rise: LCZ 2 & 0.55 & 0.07 & 0.15 & 0.4 \\
Compact Low Rise: LCZ 3 & 0.35 & 0.08 & 0.21 & 0.12 \\
Open Mid Rise: LCZ 5 & 2.17 & 1.21 & 1.94 & 2.8 \\
Open Low Rise: LCZ 6 & 20.87 & 20.67 & 25.3 & 28.35 \\
Large Lowrise: LCZ 8 & 2.16 & 1.93 & 1.3 & 1.3 \\
Sparsely Built: LCZ 9 & 0.36 & 1.63 & 1.07 & 0.39 \\
Dense Trees: LCZ A & 5.77 & 14.49 & 18.4 & 4.04 \\
Sparse Trees: LCZ B & 14.45 & 21.69 & 33.13 & 2.65 \\
Low Plants: LCZ D & 52.15 & 35.89 & 19.96 & 34.0 \\
Bare Rock - Paved: LCZ E & 0.08 & 0.06 & 0.21 & 0.02 \\
Bare Soil - Sand: LCZ F & 0.03 & 0.09 & 0.01 & 0.03 \\
\hline
\end{tabular}



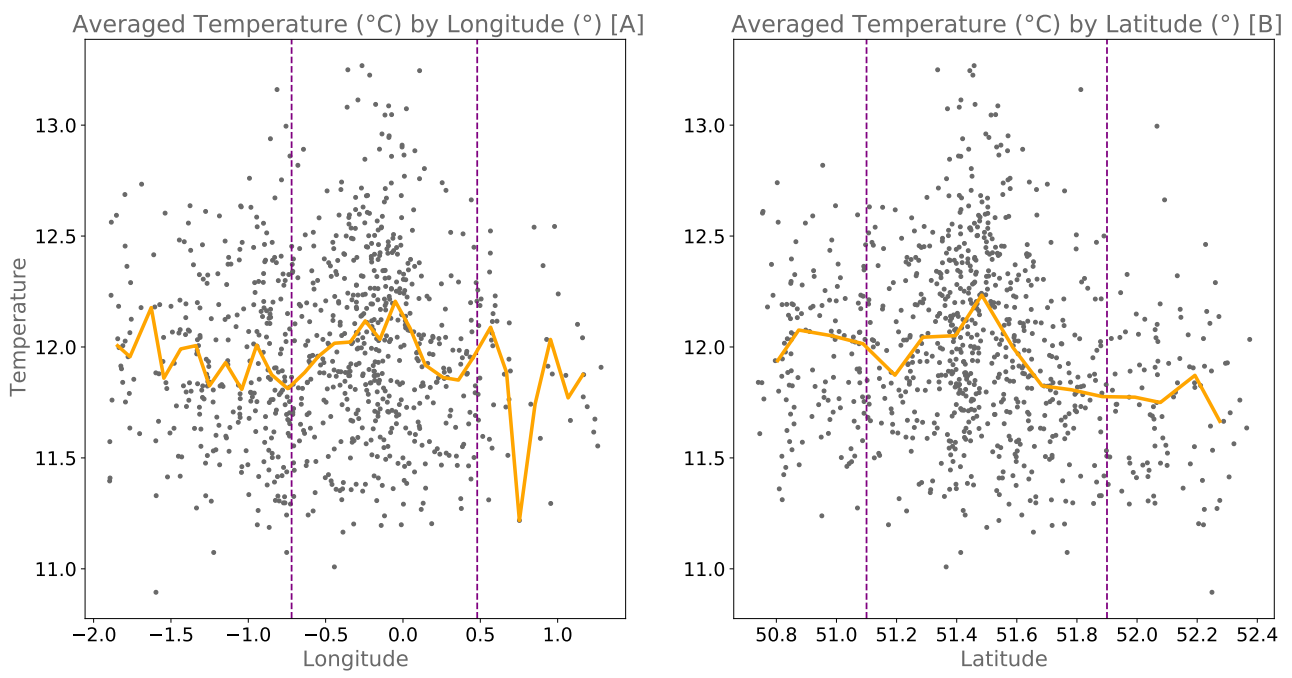

Figure S1: Averaged observed air temperature observed by Netatmo citizen weather stations depending on their latitudes and longitudes from year 2015 to 2020. Solid orange lines represent the median temperature observed by all CWS in bins of $0.05^{\circ}$. Dashed purple lines represent the Domain 2 boundaries.

\subsection{Domain Definition}

Domain 1, covering south-east England is used to acquire CWS data and study the recent seasonality of urban temperatures and daily temperature ranges across multiple towns, cities and built-up areas of varying size and location (see Supplementary Section 5.4). A specific focus on the differences between coastal and non-coastal locations is made to understand whether and where coastal influence is captured by citizen weather stations. We chose this specific domain as it includes multiple important secondary cities around London - eg., Reading, Brighton, Ramsgate, etc. - embedded in a variety of local environments ranging from forest, grass- and crop-lands or coastal areas. The simple and preliminary analysis performed in Domain 1 further serves the definition of Domain 2 and provides a general understanding of the regional specificities of the climate.

Domain 2, obtained via the analysis performed in Domain 1 and a look at the latitudinal and longitudinal distribution of air temperatures (Figure S1), is focused on the Greater London area and its direct surroundings. This domain is expected to rarely be subject to coastal sea breezes making it a suitable domain for studying how general atmospheric circulations are impacting UHA. Rare sea breeze effects can still be observed within London, but these only happen about a dozen of time per year and do not last more than few hours (Coceal et al., 2018). 


\subsection{Citizen Weather Stations and Local Climate Zones}

The supplementary information given below provides information on the processes followed to acquire and filter the CWS data, as well on their spatial distribution amongst different LCZ in the Domain 1 and 2.

The Getpublicdata function ran on the $29^{\text {th }}$ of June 2021 reported 1783 potential Netatmo CWS candidates for the study. Temperature measures of each CWS are then obtained based on CWS' identity codes through Getmeasure. It is important to note that the amount of available stations varies in time depending on the connection with the Netatmo server and the availability of devices at the time when the Getpublicdata function is run. The method for the data collection is explained in more detail in Meier et al. (2017) or in Venter et al. (2020).

Although outdoor modules are expected to be placed in shaded areas, users are not expected to put them at the World Meteorological Organization recommended height of $2 \mathrm{~m}$ for measuring near-surface meteorological variables. Additionally, users may still decide to put the stations close to sun-exposed walls or roofs. This can lead to high uncertainties in CWS measurements. It is also impossible to know if a device has been moved by a user after being reported to the Netatmo company. In this study, we consider this case to be marginal. To evaluate the quality of the data and to filter out unsuitable data for this study, we used the CrowdQC v1.2.0 R package developed by Grassmann et al. (2018) and used in Napoly et al. (2018). We applied the quality check removing all hourly measurements that did not pass the M4 quality-check level. The different levels of quality check are detailed in Napoly et al. (2018) and Potgieter et al. (2021). The M4 quality check resulted in a total of 1560 suitable CWS that cover part of the 6-year period (Figure 1). More recent years have more stations available on a daily basis, increasing from 243 daily available stations in 2015 to 1430 in 2020 (Figure S2).

Out of these $1560 \mathrm{CWS}$, we only kept stations that had been running for at least $80 \%$ of a year of the whole 6-year period, following Fenner, Daniel and Holtmann, Achim and Meier, Fred and Langer, Ines and Scherer, Dieter (2019). This filtered stations that partially represent the yearly climatology in the domain of interest. This reduced the number of stations to $884 \mathrm{CWS}$ out of which 163 were active at the minimum per day in 2015 and 673 at the maximum in 2020. Hence, 211 stations at the maximum have not recorded data during a day or have not passed the quality-check for that day (Figure S2). 423 of the CWS are located within Domain 2 (Table S2), with a majority (158) and a minority (81) of CWS located in the South-Western and North-Eastern quadrants, respectively. In each quadrant ( Table S2), most CWS are located in LCZ $6(\sim 68 \%$ to $\sim 81 \%)$ and in LCZ $5(\sim 1 \%$ to $\sim 14 \%$ ). Most LCZ 2 CWS are in the North-Eastern corner and LCZ 8 CWS never comprise more than $3 \%$ of the sample. CWS located in the remaining LCZ comprise less than $5 \%$ of the samples in each quadrant, except LCZ 9 in the South-Eastern quadrant and LCZ B in the North- and South-Western quadrants.

Table S2: Number of Netatmo Citizen Weather Station in each quadrant and percentages of CWS present in each Local Climate Zones (LCZ) per quadrant of Domain 2

\begin{tabular}{|r|r|r|r|r|}
\hline & NE & NW & SE & SW \\
\hline Number of Stations & 81 & 93 & 91 & 158 \\
\hline Compact Mid Rise: LCZ 2 & $5(6.17 \%)$ & $1(1.08 \%)$ & $1(1.10 \%)$ & $1(0.63 \%)$ \\
Compact Mid Rise: LCZ 3 & $1(1.23 \%)$ & $0(0.00 \%)$ & $0(0.00 \%)$ & $0(0.00 \%)$ \\
Compact Mid Rise: LCZ 5 & $11(13.58 \%)$ & $7(7.53 \%)$ & $1(1.10 \%)$ & $12(7.59 \%)$ \\
Compact Mid Rise: LCZ 6 & $55(67.90 \%)$ & $72(77.42 \%)$ & $74(81.32 \%)$ & $121(76.58 \%)$ \\
Compact Mid Rise: LCZ 8 & $1(1.23 \%)$ & $1(1.08 \%)$ & $2(2.20 \%)$ & $3(1.90 \%)$ \\
Compact Mid Rise: LCZ 9 & $1(1.23 \%)$ & $0(0.00 \%)$ & $5(5.49 \%)$ & $2(1.27 \%)$ \\
Compact Mid Rise: LCZ A & $0(0.00 \%)$ & $2(2.15 \%)$ & $2(2.20 \%)$ & $7(4.43 \%)$ \\
Compact Mid Rise: LCZ B & $2(2.47 \%)$ & $7(7.53 \%)$ & $3(3.30 \%)$ & $11(6.96 \%)$ \\
Compact Mid Rise: LCZ D & $4(4.94 \%)$ & $3(3.23 \%)$ & $3(3.30 \%)$ & $1(0.63 \%)$ \\
\hline
\end{tabular}

After filtering prevailing winds based on their constant origin, about $70 \%$ of the 51943 available wind measurements are kept. The filtering slightly influenced the proportion of each classes of winds: 


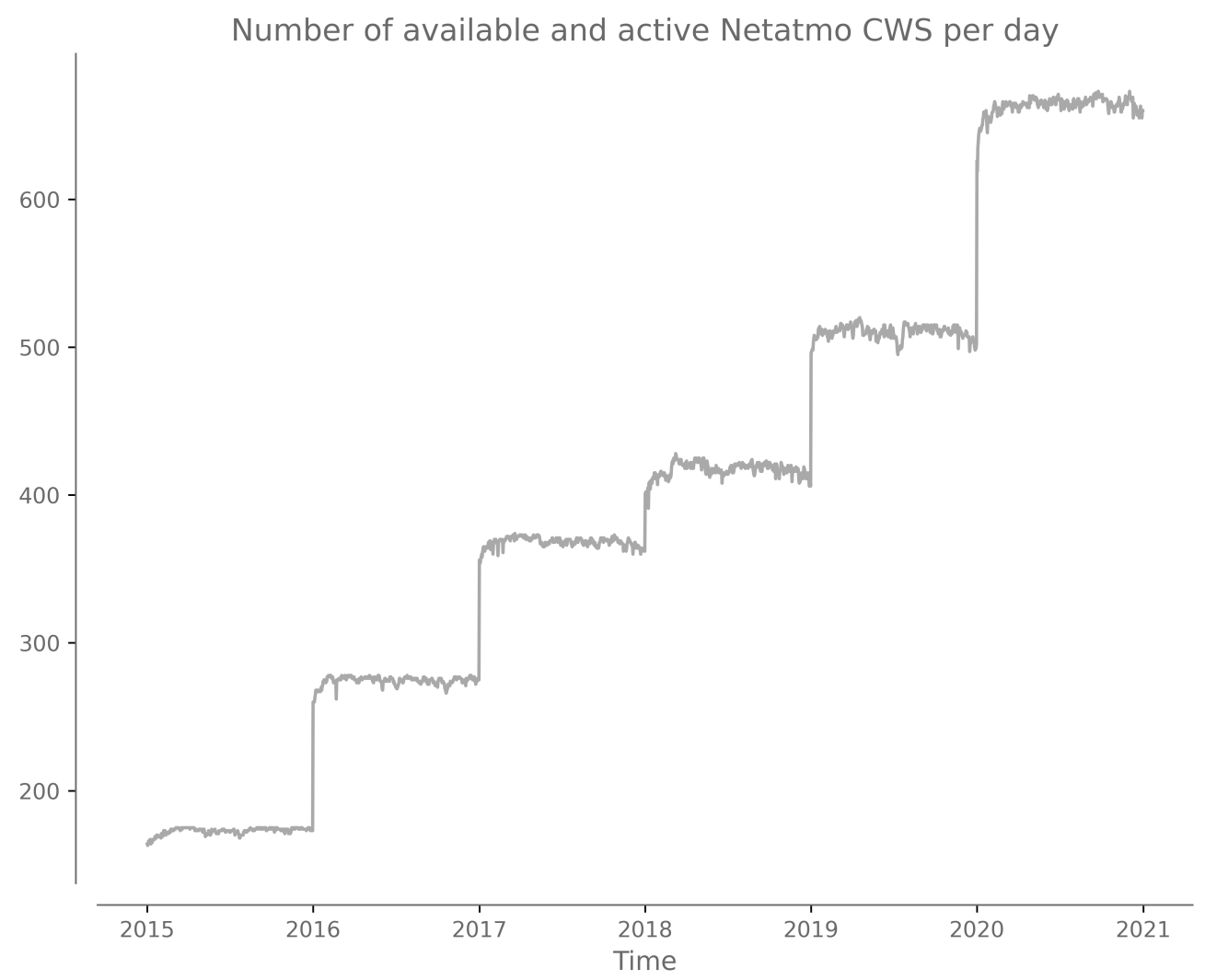

Figure S2: Number of available and quality-checked Netatmo Citizen Weather Stations in Domain 1 per day from the $1^{\text {st }}$ of January 2015 to the $31^{\text {st }}$ of December 2020. 
Table S3: Number of hours for each wind regime per season and maximum percentage of active citizen weather stations during these hours (in parenthesis).

\begin{tabular}{|c|c|c|c|c|}
\hline & DJF & MAM & $\overline{\text { JJA }}$ & SON \\
\hline \multicolumn{5}{|c|}{ North-Easterly winds (0-90 ○) } \\
\hline Calm or Light Breeze & $456(100 \%)$ & $849(100 \%)$ & $539(100 \%)$ & $842(100 \%)$ \\
\hline Gentle to Moderate Breeze & $480(100 \%)$ & $1612(100 \%)$ & $732(100 \%)$ & $883(100 \%)$ \\
\hline Moderate to Fresh Breeze & $73(97.87 \%)$ & $304(100 \%)$ & $45(98.82 \%)$ & $55(95.51 \%)$ \\
\hline Strong Breeze & 0 & $8(88.89 \%)$ & 0 & $1(76.6 \%)$ \\
\hline \multicolumn{5}{|c|}{ South-Easterly winds $(90-180 \circ)$} \\
\hline Calm or Light Breeze & $290(100 \%)$ & $228(100 \%)$ & $194(100 \%)$ & $228(100 \%)$ \\
\hline Gentle to Moderate Breeze & $839(100 \%)$ & $683(100 \%)$ & $459(100 \%)$ & $785(100 \%)$ \\
\hline Moderate to Fresh Breeze & $228(100 \%)$ & $190(100 \%)$ & $96(100 \%)$ & $124(100 \%)$ \\
\hline Strong Breeze & $13(96.45 \%)$ & $12(79.43 \%)$ & $3(86.05 \%)$ & $12(93.62 \%)$ \\
\hline \multicolumn{5}{|c|}{ South-Westerly winds $(180-270 \circ)$} \\
\hline Calm or Light Breeze & $423(100 \%)$ & $310(100 \%)$ & $567(100 \%)$ & $452(100 \%)$ \\
\hline Gentle to Moderate Breeze & $2240(100 \%)$ & $1411(100 \%)$ & $2670(100 \%)$ & $2060(100 \%)$ \\
\hline Moderate to Fresh Breeze & $1644(100 \%)$ & $975(100 \%)$ & $1404(100 \%)$ & $1182(100 \%)$ \\
\hline Strong Breeze & $775(100 \%)$ & $290(100 \%)$ & $220(100 \%)$ & $284(100 \%)$ \\
\hline \multicolumn{5}{|c|}{ North-Westerly winds (270-360 ○) } \\
\hline Calm or Light Breeze & $945(100 \%)$ & $881(100 \%)$ & $823(100 \%)$ & $1136(100 \%)$ \\
\hline Gentle to Moderate Breeze & $924(100 \%)$ & $899(100 \%)$ & $960(100 \%)$ & $948(100 \%)$ \\
\hline Moderate to Fresh Breeze & $234(99.79 \%)$ & $138(99.82 \%)$ & $88(100 \%)$ & $129(100 \%)$ \\
\hline Strong Breeze & $27(95.51 \%)$ & $40(77.78 \%)$ & 0 & $8(91.02 \%)$ \\
\hline
\end{tabular}

around $25.33 \%$ of the measurements are then Calm or Light Breeze; $51.04 \%$, Gentle to Moderate Breeze; $18.98 \%$, Moderate to Fresh Breeze; and $4.65 \%$, Strong Breeze. South-westerly winds are the most prevailing winds during the 6-year period in all seasons (Figure S3 and Table S3). During spring, however, north-easterly winds are often observed. In all seasons, most winds are classified as Gentle to Moderate Breeze, although north-westerly winds tend to also present many events of Calm or Light Breezes. Stronger winds classified as Moderate to Fresh Breezes are mostly present in south-westerly wind regimes during winter months (Table S3). North-westerly and south-easterly are generally lighter but few strong events are still detected (Figure S3). 

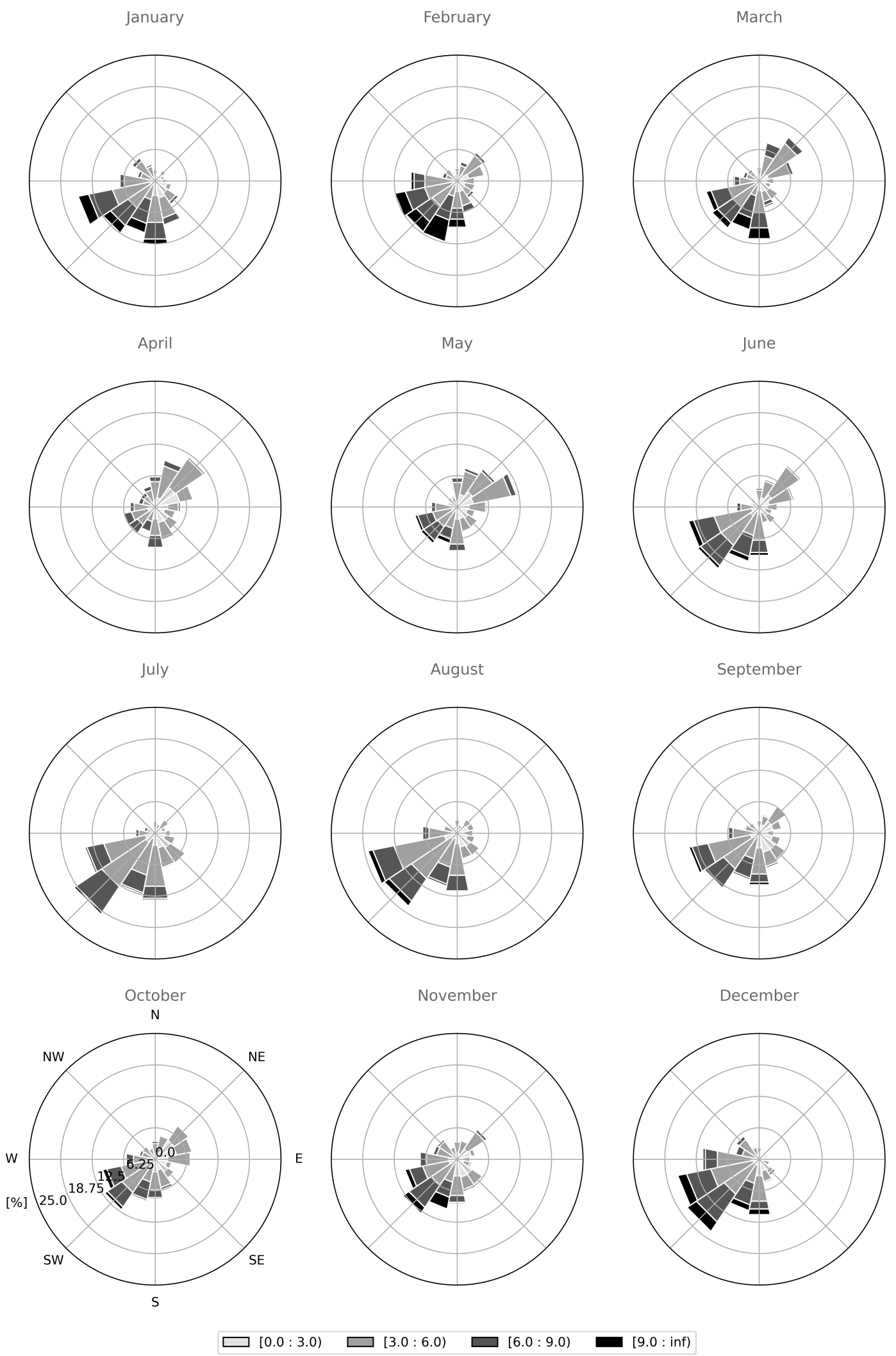

Figure S3: Monthly wind roses of observed hourly wind speed (in meters per second) and direction at Heathrow Airport from 2015 to 2020 after filtering 20 ut hours when winds are not originating from the same $90 \circ$ quadrants for at least 3 hours. Each bin corresponds to a separate wind regime class. 

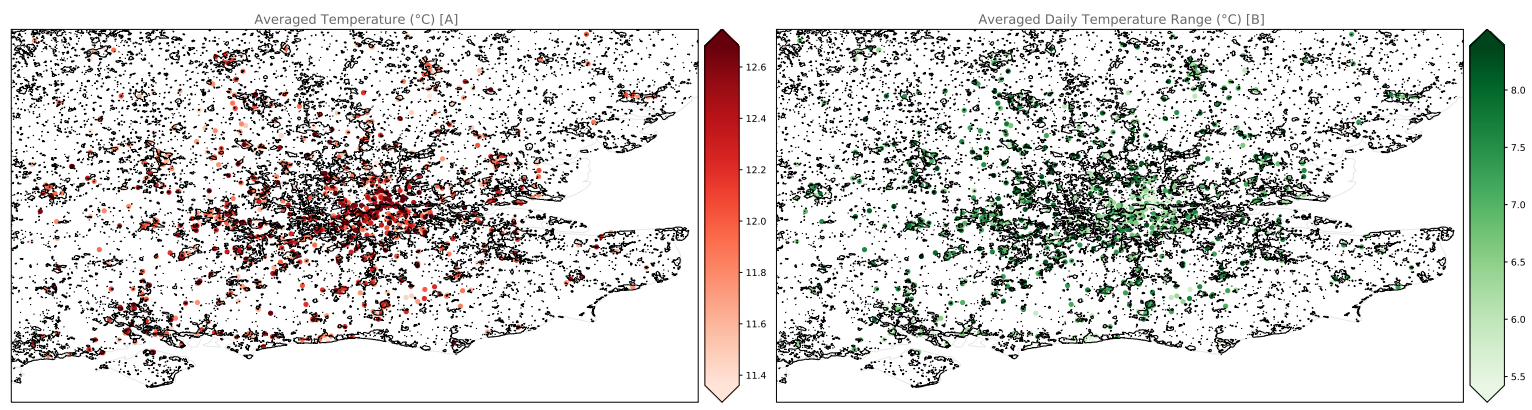

As our data covers a 6-year period, and because we also study the seasonality of air temperature among different LCZs, our study in Domain 1 uses daily averages and diurnal ranges of air temperature, which consist of the difference between the minimum and the maximum temperature per day (Figure S4 to Figure S6). The results of this preliminary analysis are given in below.

Figure S4: Averaged observed air temperature and daily temperature ranges by Netatmo citizen weather stations from year 2015 to 2020 . Color bars are scaled from the $5^{\text {th }}$ to the $95^{\text {th }}$ percentiles.

\subsection{Quasi-climatology analysis in the Domain 1: south-east England}

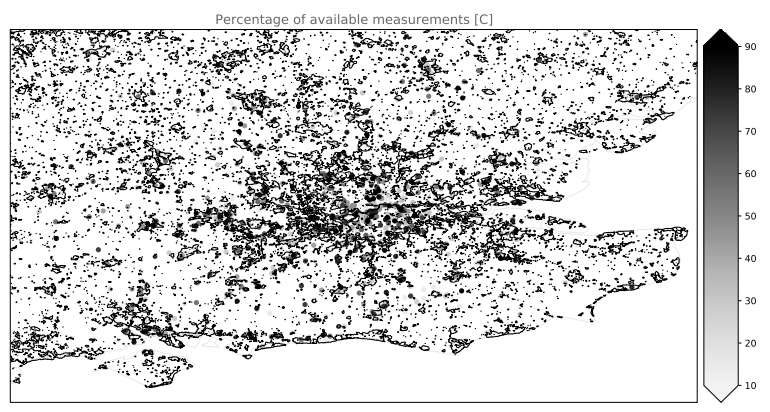

The averaged temperature observed by the CWS over the 6-year period in the Greater London area are generally higher by $\sim 1.0{ }^{\circ} \mathrm{C}$ to $\sim 1.5^{\circ} \mathrm{C}$ than the temperatures observed by CWS outside the area. The averaged diurnal temperature range is also lower by $\sim 2.5^{\circ} \mathrm{C}$ to $\sim 3.0^{\circ} \mathrm{C}$ (Figure S4). The average of the 6-year averaged temperature measured by all CWS is $12.0{ }^{\circ} \mathrm{C}$, the maximum $13.3^{\circ} \mathrm{C}$ and the minimum $10.9^{\circ} \mathrm{C}$. The standard deviation is $0.40^{\circ} \mathrm{C}$ among all CWS and the six years. The averaged daily temperature range reaches up to $9.4{ }^{\circ} \mathrm{C}$ and down to $3.6^{\circ} \mathrm{C}$ with an average of $7.1^{\circ} \mathrm{C}$ and a standard deviation of $0.9^{\circ} \mathrm{C}$ among all CWS. No particular spatial pattern is observable in terms of temporal coverage of the CWS.

When looking at the seasonal spatio-temporal variability of air temperature (Figure S5), there is a notable urban heat island effect towards the center of the Greater London area, captured by the Netatmo CWS ranging from $\sim 1.0^{\circ} \mathrm{C}$ to $\sim 2.0^{\circ} \mathrm{C}$. Similarly, daily temperature ranges tend to be smaller by $\sim 1.5^{\circ} \mathrm{C}$ to $\sim 7.0{ }^{\circ} \mathrm{C}$, depending on the season. The difference in urban heat is most noticeable during autumn (September - October - November; SON) and winter months (December - January February; DJF), with a strong urban heat island in the center of the Greater London area. During these months, CWS also capture the warmer coastal climate. Conversely, a cooler coastal climate during spring (March - April - May; MAM) and summer months (June - July - August; JJA) is observed. 
On average, temperatures measured by CWS located close to the southern coast are higher than those north of London and depict lower daily temperature ranges. The east coast appears to have very low influence on the averaged temperatures. The latter defends the choice of Domain 2 for the subsequent urban heat advection (UHA) analysis.

A noticeable inter-LCZ difference is also captured (Figure S6, upper panel). Looking at the crossCWS average of monthly median temperatures per CWS in each LCZ, we can see that more urbanized areas like compact or open mid-rises and lightweight lowrises (LCZ 2, LCZ 5 and LCZ 8, respectively) are generally $\sim 1.5{ }^{\circ} \mathrm{C}$ to $\sim 2{ }^{\circ} \mathrm{C}$ hotter than more vegetated and openly built areas located in the outskirts of the cities, like open low-rises, sparsely built or natural LCZs (LCZ 6, LCZ 9, LCZ A, LCZ B and LCZ D). This is valid for the average and $25^{t h}$ and $75^{t h}$ percentiles of the monthly median temperatures per CWS. Daily temperature ranges are also always smaller in the more central LCZs than in the more vegetated LCZs. In addition, it appears that there is an important intra-LCZ variability in terms of median temperatures and daily temperature ranges (Figure S6, bottom panel). This can be explained by the location of each CWS. Nevertheless, the land-use land-cover impact on temperatures seems to be consistent across the whole Domain 1. We also see that the range of median monthly daily temperature range among CWS in similar LCZ decreases during winter and increases during summer with $25^{t h}$ and $75^{t h}$ percentiles separated by $\sim 4^{\circ} \mathrm{C}$ for the former and $\sim 6{ }^{\circ} \mathrm{C}$ for the latter. This range remains however rather constant for monthly median air temperature with $25^{t h}$ and $75^{\text {th }}$ percentiles separated by $\sim 4{ }^{\circ} \mathrm{C}$ throughout the year.

This can be explained by the location of each CWS. Nevertheless, the land-use land-cover impact on temperatures seems to be consistent across the whole Domain 1. We also see that the range of median monthly daily temperature range among CWS in similar LCZ decreases during winter and increases during summer with $25^{\text {th }}$ and $75^{\text {th }}$ percentiles separated by $\sim 4{ }^{\circ} \mathrm{C}$ for the former and $\sim 6{ }^{\circ} \mathrm{C}$ for the latter. This range remains however rather constant for monthly median air temperature with $25^{\text {th }}$ and $75^{\text {th }}$ percentiles separated by $\sim 4^{\circ} \mathrm{C}$ throughout the year.

Hence, we find that urban areas located near the coast show similar air temperature during autumn and winter seasons than Greater London. Yet, during spring and summer, coastal cities show lower air temperature. Besides, we found that neighborhoods located in the northern parts of the Greater London are subject to cool air inflows from upwind conditions, lowering their temperatures by down to about $-2.5{ }^{\circ} \mathrm{C}$ and $-2.0{ }^{\circ} \mathrm{C}$ in the compact and open mid-rises (LCZ 2 and LCZ 5), respectively (see Table 2). Such phenomena will require future studies on local climate dynamics to try to explain why northern parts are predominantly subject to cool air breezes. Although this seems intuitive, we could not show statistical significance on the latter. Potential explanations may be related to the more wooded lands in the south of Greater London that would act as natural barriers against the propagation of hotter air coming from the south. 

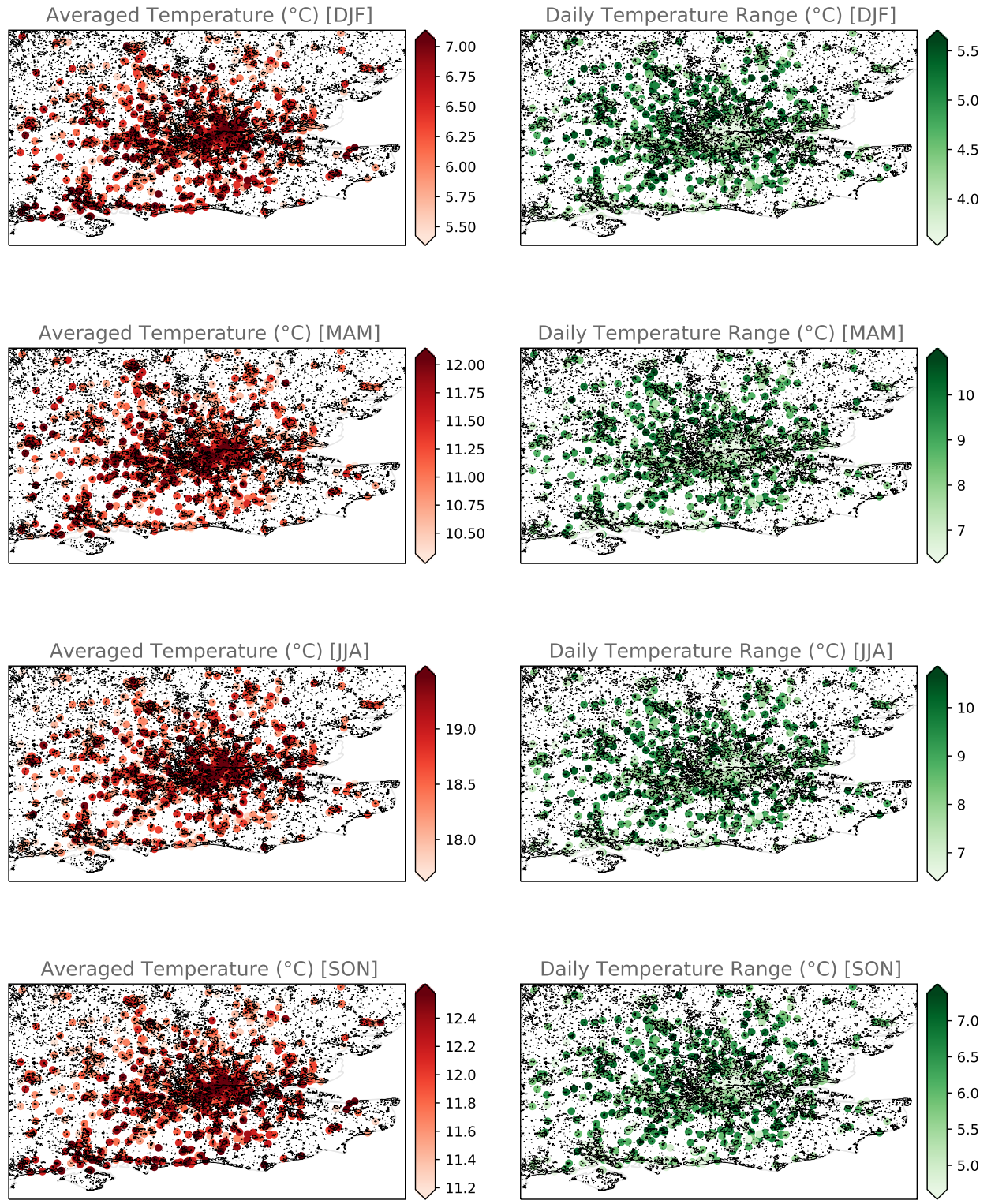

Figure S5: Seasonal averaged observed air temperature and daily temperature ranges by Netatmo citizen weather stations for years 2015 to 2020. Winter months are December - January - February (DJF); spring months are March - April - May (MAM); summer months are June - July - August (JJA); and autumn months are September - Octogzer - November (SON). Color bars are scaled from the $5^{\text {th }}$ to the $95^{\text {th }}$ percentiles. Note the different color bars in each sub-plot. 
Monthly averaged temperatures and DTR and their respective 25th and 75th percentiles per LCZ
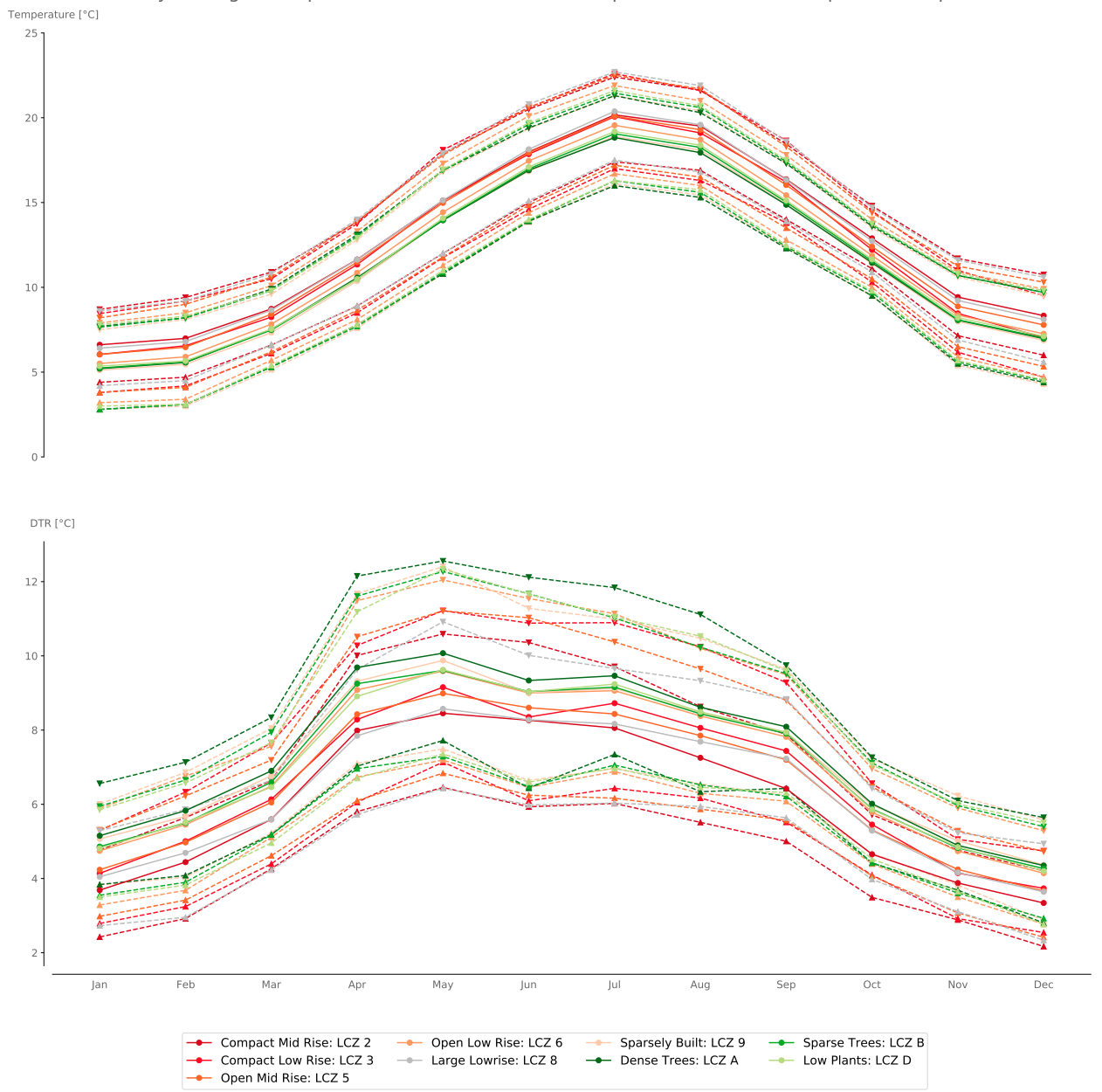

Figure S6: Cross-CWS average (full line, dotted marker) and $25^{\text {th }}$ and $75^{\text {th }}$ percentiles (dashed lines, triangles marker up and down, respectively) of CWS' monthly median temperatures and daily temperature ranges (DTR) per LCZ in degrees Celsius. 
${ }_{509} \quad$ 5.5 Additional Supplementary Materials 


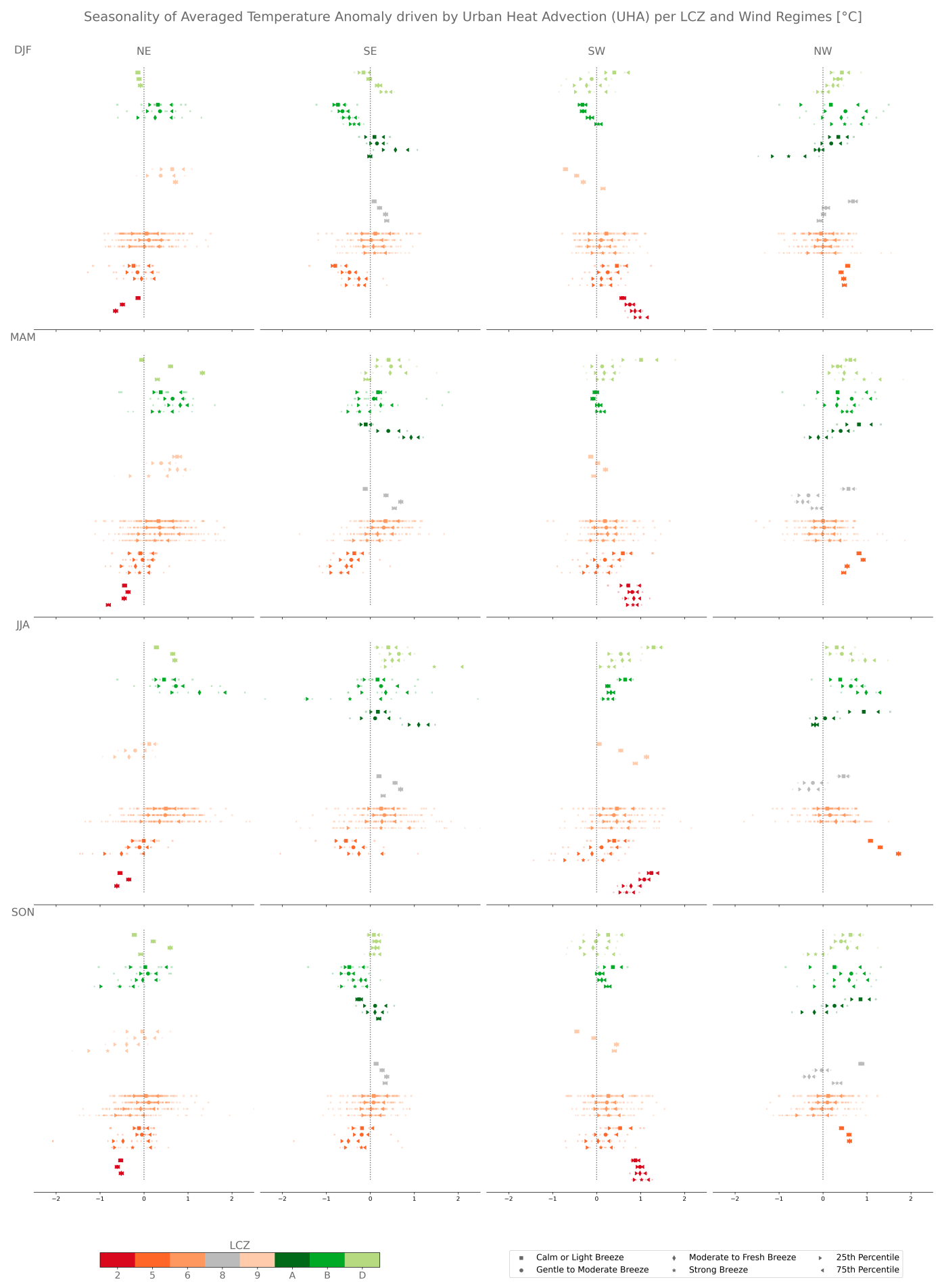

Figure S7: 6-year seasonal averaged (2015-2020) hourly urban heat advection (UHA) per downwind citizen weather station (CWS) in each Local Climiate Zone and upwind prevailing winds. Seasons consist of: December - January - February: DJF; March - April - May: MAM; September - October - November: SON; June - July - August: JJA. Large markers represent the cross-CWS median of the averaged UHA and triangle whiskers represent the $25^{t h}$ and $75^{\text {th }}$ percentiles. 


\section{References}

Bassett R, Cai X, Chapman L, Heaviside C, Thornes JE, Muller CL, Young DT, Warren EL (2016) Observations of urban heat island advection from a high-density monitoring network. Quarterly Journal of the Royal Meteorological Society 142, 2434-2441

Bassett R, Janes-Bassett V, Phillipson J, Young P, Blair G (2021) Climate driven trends in london's urban heat island intensity reconstructed over 70 years using a generalized additive model. Urban Climate 40, 100990

Bechtel B, Alexander PJ, Böhner J, Ching J, Conrad O, Feddema J, Mills G, See L, Stewart I (2015) Mapping local climate zones for a worldwide database of the form and function of cities. ISPRS International Journal of Geo-Information 4, 199-219

Bechtel B, Demuzere M, Sismanidis P, Fenner D, Brousse O, Beck C, Van Coillie F, Conrad O, Keramitsoglou I, Middel A, et al. (2017) Quality of crowdsourced data on urban morphology - the human influence experiment (huminex). Urban Science 1, 15

Bell S, Cornford D, Bastin L (2015) How good are citizen weather stations? addressing a biased opinion. Weather 70, 75-84

Benjamin K, Luo Z, Wang X (2021) Crowdsourcing urban air temperature data for estimating urban heat island and building heating/cooling load in london. Energies 14, 5208

Brousse O, Georganos S, Demuzere M, Dujardin S, Lennert M, Linard C, Snow R, Thiery W, Van Lipzig NP (2020) Can we use local climate zones for predicting malaria prevalence across sub-saharan african cities? Environmental Research Letters 15, 124051

Brousse O, Georganos S, Demuzere M, Vanhuysse S, Wouters H, Wolff E, Linard C, Nicole PM, Dujardin S (2019) Using local climate zones in sub-saharan africa to tackle urban health issues. Urban climate 27, 227-242

Chandler TJ (1965) The climate of London (Hutchinson)

Chapman L, Bell C, Bell S (2017) Can the crowdsourcing data paradigm take atmospheric science to a new level? a case study of the urban heat island of london quantified using netatmo weather stations. International Journal of Climatology 37, 3597-3605

Chen J, Saunders K, Whan K (2021) Quality control and bias adjustment of crowdsourced wind speed observations. Quarterly Journal of the Royal Meteorological Society

Ching J, Mills G, Bechtel B, See L, Feddema J, Wang X, Ren C, Brousse O, Martilli A, Neophytou M, et al. (2018) Wudapt: An urban weather, climate, and environmental modeling infrastructure for the anthropocene. Bulletin of the American Meteorological Society 99, 1907-1924

Coceal O, Bohnenstengel SI, Kotthaus S (2018) Detection of sea-breeze events around london using a fuzzy-logic algorithm. Atmospheric Science Letters 19, e846

de Vos LW, Droste AM, Zander MJ, Overeem A, Leijnse H, Heusinkveld BG, Steeneveld GJ, Uijlenhoet R (2020) Opportunistic sensing networks: A study in amsterdam. Bulletin of the American Meteorological Society 101, 313-318

de Vos LW, Leijnse H, Overeem A, Uijlenhoet R (2019) Quality control for crowdsourced personal weather stations to enable operational rainfall monitoring. Geophysical Research Letters 46, 88208829

Demuzere M, Bechtel B, Middel A, Mills G (2019) Mapping europe into local climate zones. PloS one 14, e0214474 
Demuzere M, Hankey S, Mills G, Zhang W, Lu T, Bechtel B (2020) Combining expert and crowdsourced training data to map urban form and functions for the continental us. Scientific data 7, $1-13$

Droste AM, Heusinkveld BG, Fenner D, Steeneveld GJ (2020) Assessing the potential and application of crowdsourced urban wind data. Quarterly Journal of the Royal Meteorological Society 146, 26712688

Fenner D, Bechtel B, Demuzere M, Kittner J, Meier F (2021) Crowdqc+-a quality-control for crowdsourced air-temperature observations enabling world-wide urban climate applications. Frontiers in Environmental Science p. 553

Fenner D, Meier F, Bechtel B, Otto M, Scherer D (2017) Intra and inter local climate zone variability of air temperature as observed by crowdsourced citizen weather stations in berlin, germany. Meteorologische Zeitschrift 26, 525-547

Fenner, Daniel and Holtmann, Achim and Meier, Fred and Langer, Ines and Scherer, Dieter (2019) Contrasting changes of urban heat island intensity during hot weather episodes. Environmental Research Letters 14, 124013

for National Statistics O (2021) Population estimates by output areas, electoral, health and other geographies, england and wales: mid-2020. Data retrieved online, https://www.ons.gov.uk/ peoplepopulationandcommunity/populationandmigration/populationestimates/bulletins/ annualsmallareapopulationestimates/mid2020

Goodess C, Berk S, Ratna SB, Brousse O, Davies M, Heaviside C, Moore G, Pineo H (2021) Climate change projections for sustainable and healthy cities. Buildings $\mathscr{E}$ cities 2, 812

Grassmann T, Napoly A, Meier F, Fenner D (2018) Quality control for crowdsourced data from cws

Grawe D, Thompson HL, Salmond JA, Cai XM, Schlünzen KH (2013) Modelling the impact of urbanisation on regional climate in the greater london area. International Journal of Climatology $\mathbf{3 3}$, $2388-2401$

Grimmond C (2006) Progress in measuring and observing the urban atmosphere. Theoretical and Applied Climatology 84, 3-22

Grimmond C, Oke TR (1999) Aerodynamic properties of urban areas derived from analysis of surface form. Journal of Applied Meteorology and Climatology 38, 1262-1292

Hall D, Macdonald R, Walker S, Mavroidis I, Higson H, Griffiths R (1997) Visualisation studies of flows in simulated urban arrays. Client Report 39, 97

Hammerberg K, Brousse O, Martilli A, Mahdavi A (2018) Implications of employing detailed urban canopy parameters for mesoscale climate modelling: a comparison between wudapt and gis databases over vienna, austria. International Journal of Climatology 38, e1241-e1257

Heaviside C, Cai XM, Vardoulakis S (2015) The effects of horizontal advection on the urban heat island in birmingham and the west midlands, united kingdom during a heatwave. Quarterly Journal of the Royal Meteorological Society 141, 1429-1441

Jin L, Schubert S, Fenner D, Meier F, Schneider C (2021) Integration of a building energy model in an urban climate model and its application. Boundary-Layer Meteorology 178, 249-281

Martilli A, Krayenhoff ES, Nazarian N (2020) Is the urban heat island intensity relevant for heat mitigation studies? Urban Climate 31, 100541 
Mavrogianni A, Davies M, Batty M, Belcher S, Bohnenstengel S, Carruthers D, Chalabi Z, Croxford B, Demanuele C, Evans S, et al. (2011) The comfort, energy and health implications of london's urban heat island. Building Services Engineering Research and Technology 32, 35-52

Meier F, Fenner D, Grassmann T, Jänicke B, Otto M, Scherer D (2015) Challenges and benefits from crowd sourced atmospheric data for urban climate research using berlin, germany, as testbed. In ICUC9-9th International Conference on Urban Climate jointly with 12th Symposium on the Urban Environment, volume 7

Meier F, Fenner D, Grassmann T, Otto M, Scherer D (2017) Crowdsourcing air temperature from citizen weather stations for urban climate research. Urban Climate 19, 170-191

Muller C, Chapman L, Johnston S, Kidd C, Illingworth S, Foody G, Overeem A, Leigh R (2015) Crowdsourcing for climate and atmospheric sciences: Current status and future potential. International Journal of Climatology 35, 3185-3203

Muller CL, Chapman L, Grimmond C, Young DT, Cai X (2013) Sensors and the city: a review of urban meteorological networks. International Journal of Climatology 33, 1585-1600

Napoly A, Grassmann T, Meier F, Fenner D (2018) Development and application of a statisticallybased quality control for crowdsourced air temperature data. Frontiers in Earth Science 6, 118

Office M (2020) Midas open: Uk hourly weather observation data, v202007. centre for environmental data analysis, 21 october 2020. Data retrieved online, doi:10.5285/ $8 d 85 f 664 f$ c614ba0a28af3a2d7ef 4533

Oke TR (1982) The energetic basis of the urban heat island. Quarterly Journal of the Royal Meteorological Society 108, 1-24

Oke TR, Mills G, Christen A, Voogt JA (2017) Urban climates (Cambridge University Press)

Oke TR, et al. (2004) Initial guidance to obtain representative meteorological observations at urban sites

Pachauri RK, Allen MR, Barros VR, Broome J, Cramer W, Christ R, Church JA, Clarke L, Dahe Q, Dasgupta P, et al. (2014) Climate change 2014: synthesis report. Contribution of Working Groups I, II and III to the fifth assessment report of the Intergovernmental Panel on Climate Change (Ipcc)

Potgieter J, Nazarian N, Lipson MJ, Hart MA, Ulpiani G, Morrison W, Benjamin K (2021) Combining high-resolution land use data with crowdsourced air temperature to investigate intra-urban microclimate. Frontiers in Environmental Science p. 385

Ren C, Cai M, Li X, Zhang L, Wang R, Xu Y, Ng E (2019) Assessment of local climate zone classification maps of cities in china and feasible refinements. Scientific reports $\mathbf{9}, 1-11$

Souch C, Grimmond S (2006) Applied climatology: urban climate. Progress in physical geography 30, $270-279$

Steeneveld GJ, Koopmans S, Heusinkveld B, Van Hove L, Holtslag A (2011) Quantifying urban heat island effects and human comfort for cities of variable size and urban morphology in the netherlands. Journal of Geophysical Research: Atmospheres 116

Stewart ID (2011) A systematic review and scientific critique of methodology in modern urban heat island literature. International Journal of Climatology 31, 200-217

Stewart ID, Oke TR (2012) Local climate zones for urban temperature studies. Bulletin of the American Meteorological Society 93, 1879-1900 
Sunter M (2021) Midas data user guide for uk land observations, v20210705. documentation. met office.

Varentsov M, Fenner D, Meier F, Samsonov T, Demuzere M (2021) Quantifying local-and meso-scale drivers of moscow's urban heat island with reference and crowdsourced observations. Frontiers in Environmental Science p. 543

Varentsov M, Konstantinov P, Shartova N, Samsonov T, Kargashin P, Varentsov A, Fenner D, Meier F (2020) Urban heat island of the moscow megacity: the long-term trends and new approaches for monitoring and research based on crowdsourcing data. In IOP Conference Series: Earth and Environmental Science, volume 606, p. 012063 (IOP Publishing)

Venter ZS, Brousse O, Esau I, Meier F (2020) Hyperlocal mapping of urban air temperature using remote sensing and crowdsourced weather data. Remote Sensing of Environment 242, 111791

Venter ZS, Chakraborty T, Lee X (2021) Crowdsourced air temperatures contrast satellite measures of the urban heat island and its mechanisms. Science Advances 7, eabb9569

Vulova S, Meier F, Fenner D, Nouri H, Kleinschmit B (2020) Summer nights in berlin, germany: modeling air temperature spatially with remote sensing, crowdsourced weather data, and machine learning. IEEE Journal of Selected Topics in Applied Earth Observations and Remote Sensing 13. $5074-5087$

Wolters D, Brandsma T (2012) Estimating the urban heat island in residential areas in the netherlands using observations by weather amateurs. Journal of Applied Meteorology and Climatology 51, 711721

Zumwald M, Knüsel B, Bresch DN, Knutti R (2021) Mapping urban temperature using crowd-sensing data and machine learning. Urban Climate 35, 100739 